\title{
GNREL
}

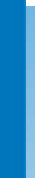

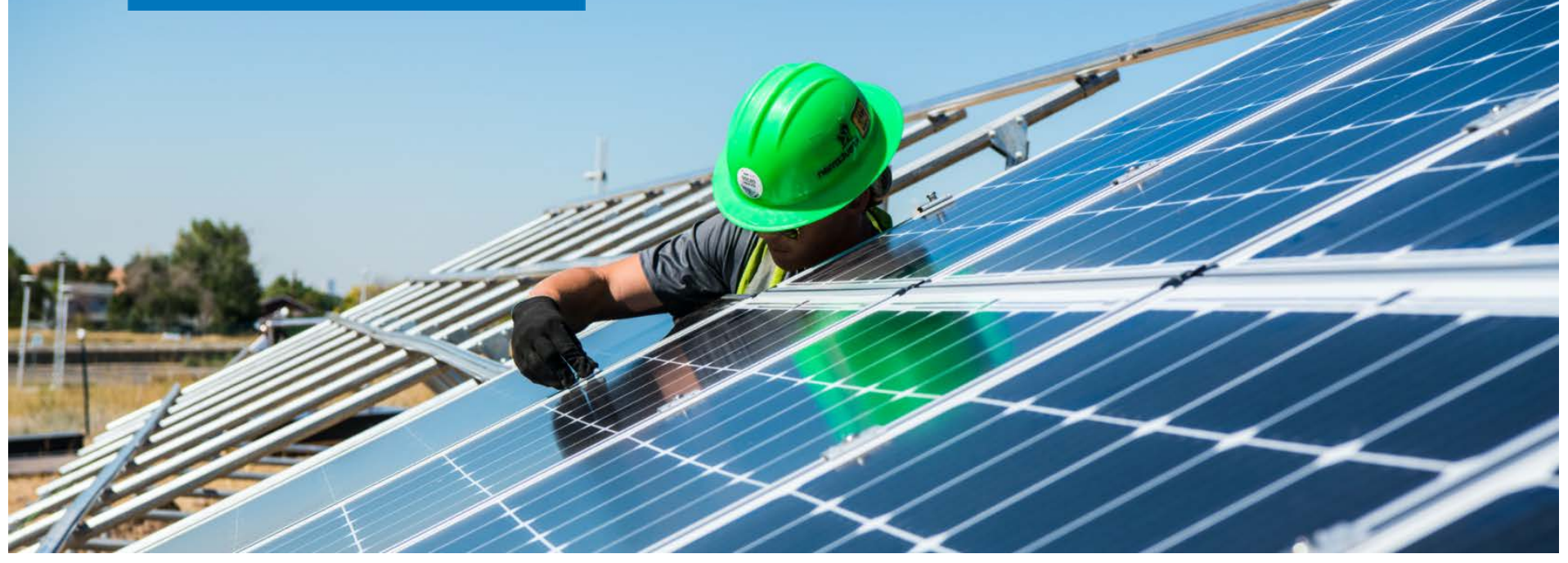

\section{Maximizing Solar and Transportation Synergies}

\author{
Kristen Ardani, Chad Hunter, Caley Johnson, \\ and Sam Koebrich
}

NREL is a national laboratory of the U.S. Department of Energy

Office of Energy Efficiency \& Renewable Energy

Operated by the Alliance for Sustainable Energy, LLC

This report is available at no cost from the National Renewable Energy Laboratory (NREL) at www.nrel.gov/publications.

\section{Technical Report}

NREL/TP-6A20-80779

September 2021 


\section{FAREL}

\section{Maximizing Solar and Transportation Synergies}

\section{Kristen Ardani, Chad Hunter, Caley Johnson, and Sam Koebrich}

\section{Suggested Citation}

Ardani, Kristen, Chad Hunter, Caley Johnson, and Sam Koebrich. 2021. Maximizing Solar and Transportation Synergies. Golden, CO: National Renewable Energy Laboratory.

NREL/TP-6A20-80779. TP-6A20-80779. https://www.nrel.gov/docs/fy21osti/80779.pdf.

NREL is a national laboratory of the U.S. Department of Energy Office of Energy Efficiency \& Renewable Energy Operated by the Alliance for Sustainable Energy, LLC

This report is available at no cost from the National Renewable Energy Laboratory (NREL) at www.nrel.gov/publications.

Contract No. DE-AC36-08GO28308
Technical Report

NREL/TP-6A20-80779

September 2021

National Renewable Energy Laboratory 15013 Denver West Parkway Golden, CO 80401 303-275-3000 • www.nrel.gov 


\section{NOTICE}

This work was authored by the National Renewable Energy Laboratory, operated by Alliance for Sustainable Energy, LLC, for the U.S. Department of Energy (DOE) under Contract No. DE-AC36-08GO28308. Funding provided by U.S. Department of Energy Office of Energy Efficiency and Renewable Energy Solar Energy Technologies Office. The views expressed herein do not necessarily represent the views of the DOE or the U.S. Government.

This report is available at no cost from the National Renewable Energy Laboratory (NREL) at www.nrel.gov/publications.

U.S. Department of Energy (DOE) reports produced after 1991 and a growing number of pre-1991 documents are available free via www.OSTI.gov.

Cover Photo by Dennis Schroeder: NREL 40820.

NREL prints on paper that contains recycled content. 


\section{The Solar Futures Study and Supporting Reports}

The Solar Futures Study, initiated by the U.S. Department of Energy Solar Energy Technologies Office and led by the National Renewable Energy Laboratory, envisions how, over the next few decades, solar could come to power $40 \%$ or more of U.S. electricity demand, dramatically accelerating the decarbonization of buildings, transportation, and industry.

Through state-of-the-art modeling, the Solar Futures Study is the most comprehensive review to date of the potential role of solar in decarbonizing the U.S. electric grid and broader energy system. However, not all the detailed analysis that informed the Solar Futures Study could be included within its pages. This further analysis is collected in additional National Renewable Energy Laboratory reports, each dedicated to a different technology or socioeconomic concern.

This report, Maximizing Solar and Transportation Synergies, focuses on opportunities to enable greater PV use across the transportation sector.

\section{The Solar Futures Study Reports}

- Solar Futures Study (main report)

- Research Priorities for Solar Photovoltaics in a Decarbonized U.S. Grid

- $\quad$ The Role of Concentrating Solar-Thermal Power Technologies in a Decarbonized U.S. Grid

- The Demand-Side Opportunity: The Roles of Distributed Solar and Building Energy Systems in a Decarbonized Grid

- Maximizing Solar and Transportation Synergies

- $\quad$ The Potential for Electrons-to-Molecules Using Solar Energy

- Affordable and Accessible Solar for All: Barriers, Solutions, and On-Site Adoption Potential

- Forthcoming Environment and Circular Economy Report

You can learn more about the project and reports on the NREL website at https://www.nrel.gov/analysis/solar-futures.html. 


\section{Acknowledgments}

This work was funded by the U.S. Department of Energy (DOE) Solar Energy Technologies Office. The authors would like to thank the following individuals for their review of this work: Sara Baldwin (Energy Innovation), Dan Bilello (NREL), Marc Melaina (DOE Hydrogen and Fuel Cell Technologies Office), Matteo Muratori (National Renewable Energy Laboratory), Robert Margolis (NREL), and Joseph Powell (ChemePD).We also would like to thank the following individuals and organizations for their contributions to the technical review panel: Sara Baldwin (Energy Innovation), Austin Brown (UC Davis), Andrew Burnham (Argonne National Laboratory), Andrew Conley (Clean Fuels Ohio), Ben Ealey (Smart Electric Power Alliance), Natalia Mathura (Smart Electric Power Alliance), Kelley Smith Burk (Florida Office of Energy), and Aarohi Vijh (SunPower). Thank you to the following individuals for additional technical input: Stephanie Meyn (Seattle-Tacoma International Airport), Chad Reese (San Diego International Airport), Jarett Zuboy (independent contractor), and our colleagues at the National Renewable Energy Laboratory, including Brady Cowiestoll, Andrew Meintz, Bryan Pivovar, Cory Kreutzer, Josh Eichman, and Trieu Mai. 


\section{List of Acronyms}

$\mathrm{AC}$

ANL

BEV

DC

DCFC

DER

DOE

e-fuels

EFS

EV

EVSE

eVTOL

FCEV

GHG

HDV

ICE

IMO

LDV

MDV

MPDGE

NREL

NSP

PEM

PEV

PHEV

PV

R\&D

SDG\&E

SMR

TCO

TOU

V2G

VMT

VTOL alternating current

Argonne National Laboratory

battery electric vehicle

direct current

direct current fast charging station

distributed energy resource

U.S. Department of Energy

electrofuels

Electrification Futures Study

electric vehicle

electric vehicle supply equipment

electric vertical takeoff and landing

fuel cell electric vehicle

greenhouse gas

heavy-duty vehicle

internal combustion engine

International Maritime Organization

light-duty vehicle

medium-duty vehicle

miles per diesel gallon equivalent

National Renewable Energy Laboratory

network service provider

proton exchange membrane

plug-in electric vehicle

plug-in hybrid electric vehicle

photovoltaic

research and development

San Diego Gas and Electric

steam-methane reforming

total cost of ownership

time-of-use

vehicle-to-grid

vehicle miles traveled

vertical takeoff and landing 


\section{Executive Summary}

We identify the technological and market pathways that will enable better use of photovoltaic (PV) electricity as fuel for future transportation demand. Most of the pathways identified will require collaborative research and development (R\&D) efforts to improve the capabilities of multiple technologies, including PV, energy storage, vehicles, electrolyzers, electrofuels, and infrastructure (see Figure ES-1).

We find that for plug-in electric vehicles (PEVs), technologies that enable wide-scale managed and coordinated charging are among the highest priorities for continued research, development, and deployment in the near term. Furthermore, managed and coordinated charging capabilities are foundational for future vehicle-to-grid (V2G) functionality in the long term. Vehicle batteries that can withstand a higher number of charge cycles are also needed for V2G approaches that store excess PV generation and discharge it back to the grid. Higher-powered batteries could enable faster charging and improved alignment of charging loads with PV generation.

For hydrogen fuel cell electric vehicles (FCEVs), the use of PV electricity for electrolysis provides an opportunity to increase PV deployment. Specifically, flexible electrolyzers needed for hydrogen fuel production can help decrease peak grid load, reduce PV curtailment, and increase PV energy prices by providing an effective price floor for PV electricity sales. However, electrolyzers do not have access to wholesale electricity markets, which poses a barrier to fully maximizing PV deployment. With respect to vehicle technology advancements, FCEVs have the potential to support higher levels of PV penetration by acting as a flexible power generator and providing electricity back to the grid. Other long-term priorities for increasing the use of PV for hydrogen vehicles include the development of breakthrough technologies for liquefaction and hydrogen storage, as well as the buildout of hydrogen delivery and dispensing infrastructure.

For rail, air, and maritime transportation, the feasibility of increased PV use varies in the near term; opportunities for synergies with solar include the electrification of rail, increased reliability from airport microgrids, and switching from heavy fuel oil to clean maritime electrofuels made from PV-based hydrogen. Over the longer term, battery swap stations for electric airplanes and the co-location of solar with hydrogen fueling stations at shipping ports may enable greater synergies between PV and transportation. 


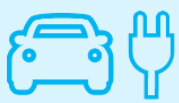

Beyond the Grid

- On-vehicle PV

- PV parking canopies

- DC-DC electric

vehicle charging

- Dedicated PV

electrolyzer plants

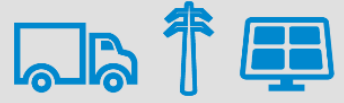

Manage the Grid:

Align Transportation Demands with Solar Production

Technological

- Standardized charging communication protocols

- Fast and flexible vehicle battery charging rates

- High-charge-rate infrastructure

- Vehicle-to-grid compatible batteries and fuel cells

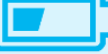

Synergize End of

Life Impacts

- Reused electric vehicle batteries for stationary grid applications

- Recycled PV silicon for vehicle batteries

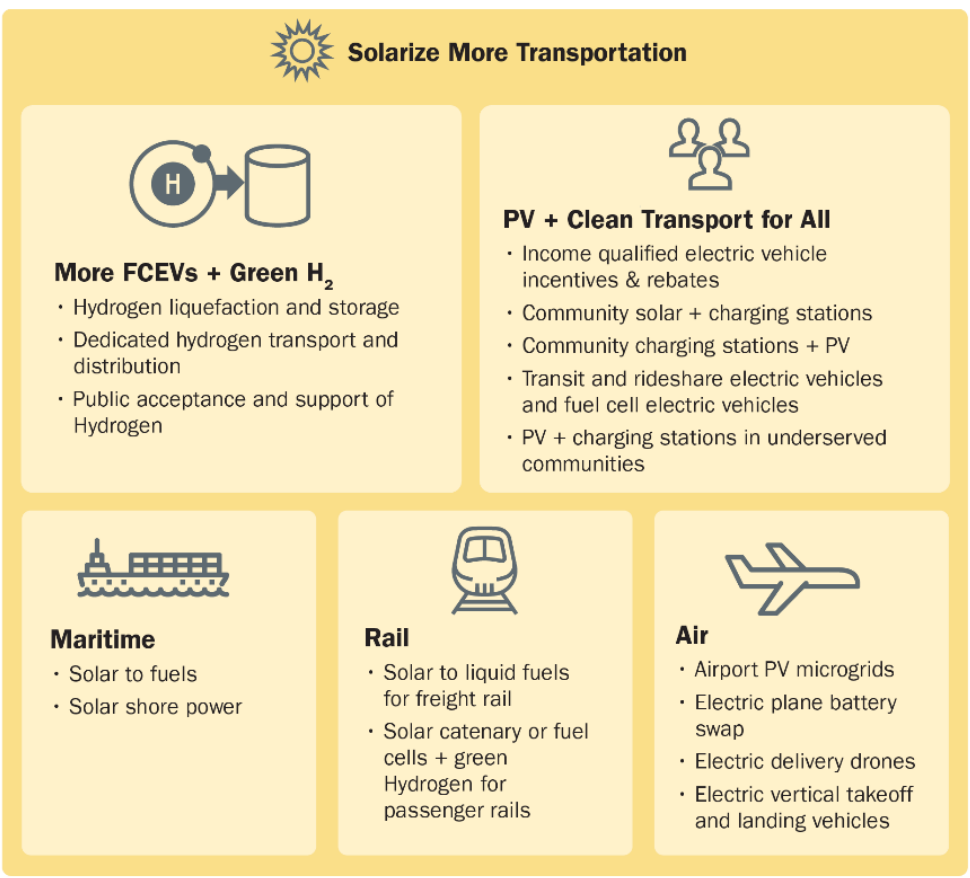

Figure ES-1. Important opportunities for maximizing PV and transportation synergies 


\section{Table of Contents}

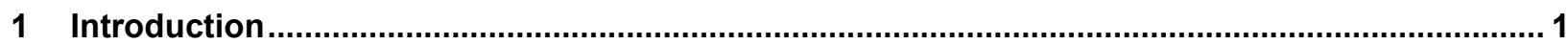

2 Opportunities and Challenges Related to PV and Plug-In Electric Vehicle Synergies ................ 2

2.1 Exploring the Future of PV and Electric Vehicles via Scenario Analysis and Modeling ............. 3

2.2 Synergies Between High-Penetration PV and PEVs: Technology Challenges and Opportunities 5

2.2.1 PV Technology Advancements for Electric Vehicles ..................................................... 5

2.2.2 Multi-Technology Advancements for Electric Vehicles................................................ 8

2.3 Non-Hardware Barriers to Co-Deployment of High-Penetration PV and Electric Vehicles........... 13

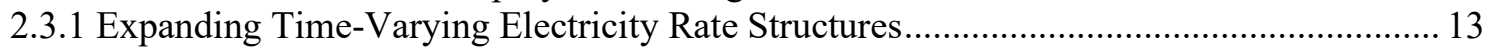

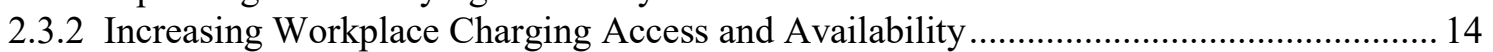

2.2.3 Overcoming Barriers to Equitable Adoption.............................................................. 15

2.2.4 Implementing Best Practices for Permitting and Interconnection................................. 15

3 Opportunities and Challenges Related to PV and Hydrogen Vehicle Synergies....................... 17

3.1 Exploring the Future of PV and Hydrogen Vehicles.............................................................. 17

3.2 Synergies Between High-Penetration PV and FCEVs: Technology Challenges and

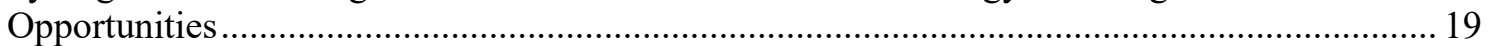

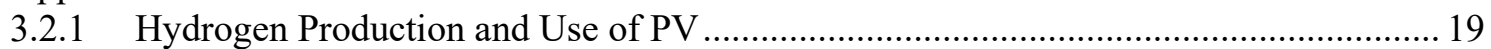

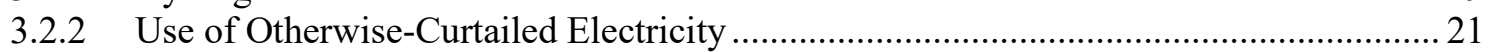

3.2.3 MDV/HDV Hydrogen Refueling Stations: Modularity of Components and PV ........... 21

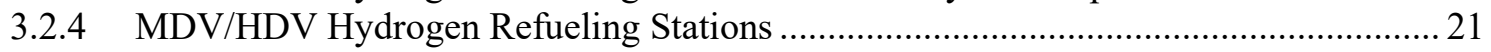

3.2.5 Breakthrough R\&D on Liquefaction and Storage .................................................... 22

3.2.6 Dedicated Hydrogen Transmission and Delivery Infrastructure.................................... 23

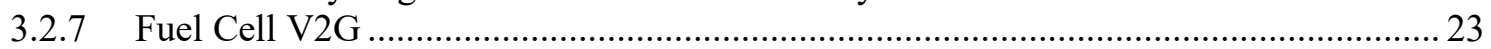

3.3 Deployment Challenges and Opportunities for PV and FCEVs ............................................. 24

3.3.1 Electrolyzer Access to Wholesale Markets ................................................................. 24

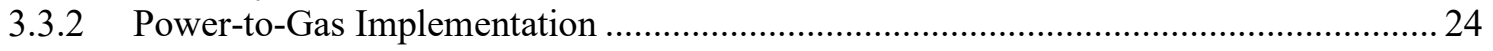

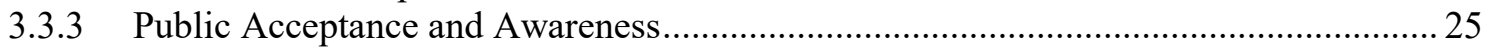

3.3.4 Public Support for Early-Stage Infrastructure Investment ........................................... 25

3.3.5 Electrolyzer, Fuel Cell, and On-Board Hydrogen Storage Costs ..................................25

4 Opportunities and Challenges for PV and Rail, Air, and Maritime Applications ........................26

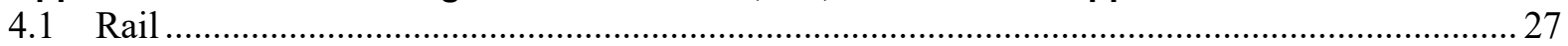

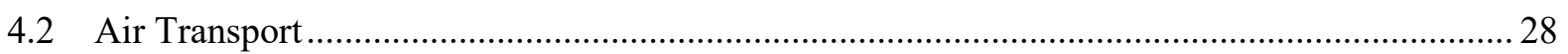

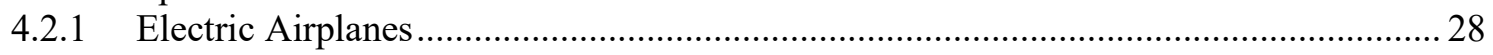

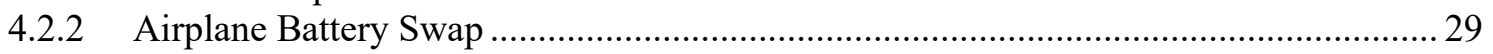

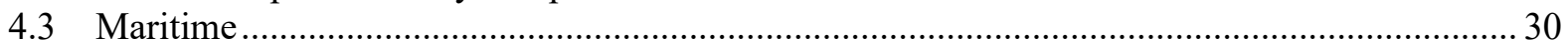

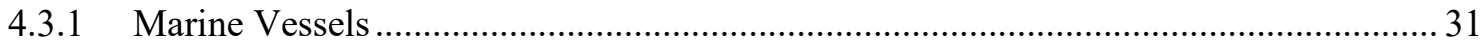

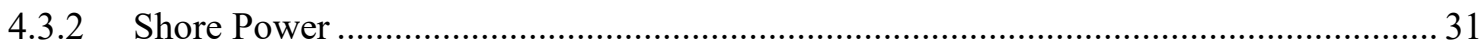

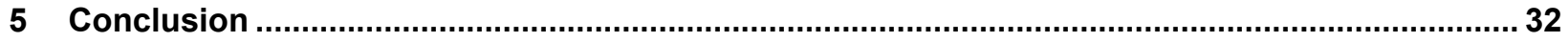

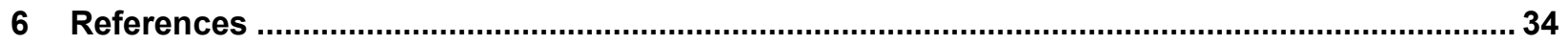

Appendix. Estimating Total Electricity Requirement for Deep Decarbonization of the

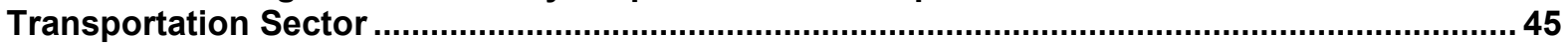




\section{List of Figures}

Figure ES-1. Important opportunities for maximizing PV and transportation synergies.........................viii

Figure 1. Example PV charging configurations: direct (left) and indirect (right)..................................... 2

Figure 2. Framework for the Core Solar Futures Scenarios ............................................................. 3

Figure 3. Modeled on-road vehicle stock from 2017-2050, by technology type, based on the Solar Futures Study Decarb+E scenario (Mai et al. 2018). "Other" includes hydrogen, natural gas, and propane fuel types.

Figure 4. Estimates of specific power (power-to-weight ratio) vs. module cost for single-junction and

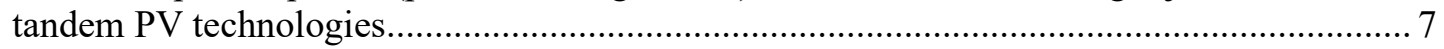

Figure 5. Modeled 2050 hourly load and PV generation for the Solar Futures Study Decarb+E scenario .. 9

Figure 6. Daily summer prices for SDG\&E pilot PEV TOU rates and Xcel Colorado TOU rate .............. 14

Figure 7. Overview of centralized vs. distributed hydrogen infrastructure for refueling FCEVs.............. 20

Figure 8. U.S. transportation sector energy use in 2020, 2035, and 2050 (U.S. Energy Information

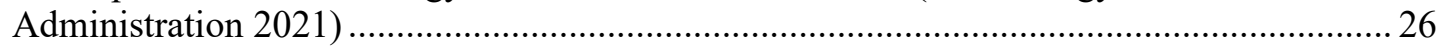

Figure 9. Volumetric and gravimetric energy density of fuels (Kobayahsi et al. 2018) ...........................29

\section{List of Tables}

Table 1. Plug-In Electric Vehicle and PV Deployment Under Solar Futures Study Core Scenarios ........... 4

Table 2. Examples of Managed and Coordinated Charging Strategies for PEVs.................................... 10

Table 3. Barriers to Co-Deployment of High-Penetration PV and Electric Vehicles, With Mitigation

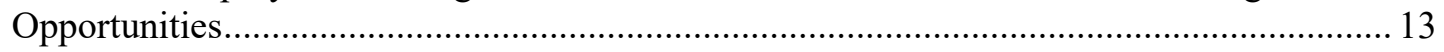

Table 4. Deployment Barriers to High-Penetration PV and FCEVs, With Mitigation Opportunities ........ 24

Table 5. Summary of Estimated Low- and Zero-Carbon Fuel Market Shares, Fuel Economy Ratios, and

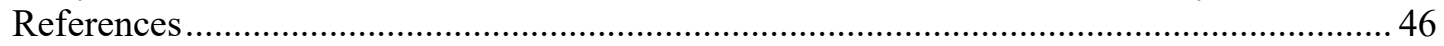

Table 6. Approximated Transportation Sector Deep Decarbonization Energy Consumption .................... 48 


\section{Introduction}

Solar photovoltaics (PV) provide a carbon-free source of electricity that may be used across the transportation sector-including in light-duty vehicles (LDVs), medium-duty vehicles (MDVs), heavy-duty vehicles (HDVs), and micromobility, as well as rail, air, and maritime applications. The use of PV for transportation will become especially important as the U.S. transportation system becomes increasingly electrified and less dependent on fossil fuels and internal combustion engine (ICE) technologies. According to the U.S. Energy Information Administration's Reference case, U.S. plug-in electric vehicle (PEV) adoption will grow from 2 million vehicles in 2020 to just over 13 million in 2035, and hydrogen fuel cell electric vehicles (FCEVs) will increase from 7,000 to 14,000 over that same period (U.S. Energy Information Administration 2021). The increase in electric and hydrogen transportation could significantly impact the future electricity system, as power system planners and utilities seek to build the generation and infrastructure needed to meet growing transportation load and possible higher peak demand. Optimizing the temporal alignment between midday PV production and transportation energy demand will be a top priority for maximizing the use of PV generation across the future transportation system. Advancements in managed charging and electrolysis, vehicle-to-grid (V2G) applications, and new market and policy mechanisms will be needed.

Over the next decade, the use of PV for vehicle charging and hydrogen fuel production can reduce transportation-sector greenhouse gas $(\mathrm{GHG})$ emissions, thereby mitigating associated climate change impacts. The transportation and power sectors are the largest contributors to total anthropogenic GHG emissions, accounting for $28 \%$ and $27 \%$ of total emissions, respectively (U.S. EPA 2018). Today, carbon-intensive fuels, such as gasoline and diesel, account for over $90 \%$ of fuel used across the U.S. transportation sector. The shift away from ICE technologies to PEV and hydrogen fuel cell technologies could reduce GHG emissions substantially. Compared to ICE vehicles, electric and hydrogen fuel cell vehicles produce, on average, $29 \%$ and $19 \%$ fewer life cycle emissions, respectively (IEA 2020b). However, to realize the full potential of PEV and hydrogen fuel cell transportation in mitigating climate change, reducing the GHG intensity of power generation through increased PV and other low-carbon resources will be required.

LDVs currently present the greatest opportunity for GHG reduction in the transportation sector because they account for more than half of transportation GHG emissions. In terms of GHG emissions, LDVs are followed by MDVs and HDVs (23\%), aircraft (9\%), trains (2\%), and ships and boats (2\%) (US EPA 2018). While rail, air, and maritime applications represent a relatively small share of total transportation sector emissions, PV can play an important role in the deep decarbonization of these sectors by enabling the production of carbon free electrofuels (e-fuels).

In this report, we discuss the potential for PV to support decarbonization of the future transportation system. We identify the technological and market pathways that will enable better use of PV electricity as fuel for future transportation demand. Most of the pathways identified will require collaborative research and development (R\&D) efforts to improve the capabilities of multiple technologies, including PV, energy storage, vehicles, and infrastructure. This report is structured as follows. Section 2 explores opportunities and challenges for PV and electric LDVs and HDVs. Section 3 focuses on PV and the infrastructure needed to produce e-fuels, primarily 
hydrogen. Section 4 explores PV and opportunities for rail, air, and maritime transportation. Section 5 summarizes key findings and potential areas for future research.

\section{Opportunities and Challenges Related to PV and Plug-In Electric Vehicle Synergies}

PEVs include plug-in hybrid electric vehicles (PHEVs), which rely on both an internal combustion engine and batteries to power an electric motor, and battery electric vehicles (BEVs), which derive all their power from electricity and thus require larger batteries. BEVs produce zero tailpipe emissions and reduce GHG emissions, especially when charged with a low-carbon electricity supply.

PV can be used to charge PEVs directly or indirectly (Figure 1). For direct charging, the electric vehicle supply equipment (EVSE) is coupled with a PV system; thus, charging is limited to onsite PV generation during the day. Direct PV charging configurations often require a stationary battery for storing PV electricity. This ensures that electricity is utilized even if it is produced when the car is not plugged in or capable of charging at the same rate that the PV is producing electricity. For indirect PV charging, the EVSE draws on PV generation supplied through the grid. Today, indirect charging is more common because it has greater timing flexibility than direct charging without storage and is more cost-effective than direct charging with storage.

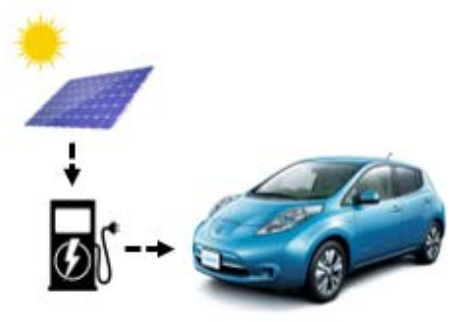

Direct PV Charging

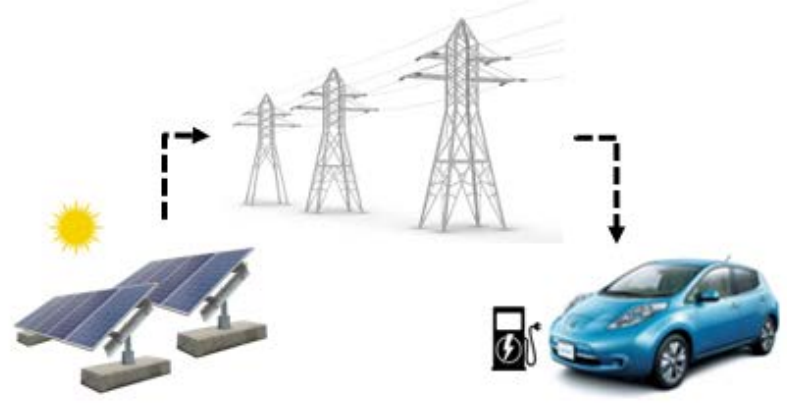

Indirect PV Charging

Figure 1. Example PV charging configurations: direct (left) and indirect (right)

BEV charging times vary widely, from less than 30 minutes to more than 20 hours, depending on the type of vehicle and EVSE used (U.S. Department of Energy 2017). PHEVs often have shorter charging times owing to the smaller batteries used. For all PEVs, charging is impacted by the availability of charging infrastructure. More than $80 \%$ of charging events occur at home, mostly in the evening, after PV production has peaked for the day (U.S. Department of Energy 2017).

PV and electric vehicle technologies continue to gain market share, but they represent a small fraction of total U.S. electricity generation and car sales. Solar energy provides approximately $2 \%$ of total U.S. electricity (U.S. Energy Information Administration 2020), while electric vehicles represent $1.8 \%$ of all new passenger vehicles sold annually (Edison Electric Institute 2019) and $0.6 \%$ of LDV stock (IEA 2020a). In addition, these two technologies are typically planned for and deployed separately, without consideration of the synergies between the two. 
As markets for electric vehicles and related charging infrastructure mature, there will be significant opportunities for synergistic PV growth.

In this section, we use Solar Futures Study scenario analysis and modeling results to explore a future with high penetration of PV and electric vehicles. We also rely on literature-based research and interviews with PV and transportation experts to identify priority technology and deployment barriers to realizing this high-penetration future, as well as potential solutions.

\subsection{Exploring the Future of PV and Electric Vehicles via Scenario Analysis and Modeling}

The Solar Futures Study examines the role of solar energy in scenarios with decarbonized U.S. electricity grids, including under high-electrification futures. The analysis examines the necessary changes to the power system, interactions between solar and other clean energy technologies, cost and emissions implications, and grid-integration challenges and opportunities under decarbonized systems. The Solar Futures Study focuses on three core scenariosReference, Decarbonization (Decarb), and Decarbonization with Electrification (Decarb+E) summarized in Figure 2 (see the DOE 2021 for further discussion of the modeling approach, assumptions, and results).

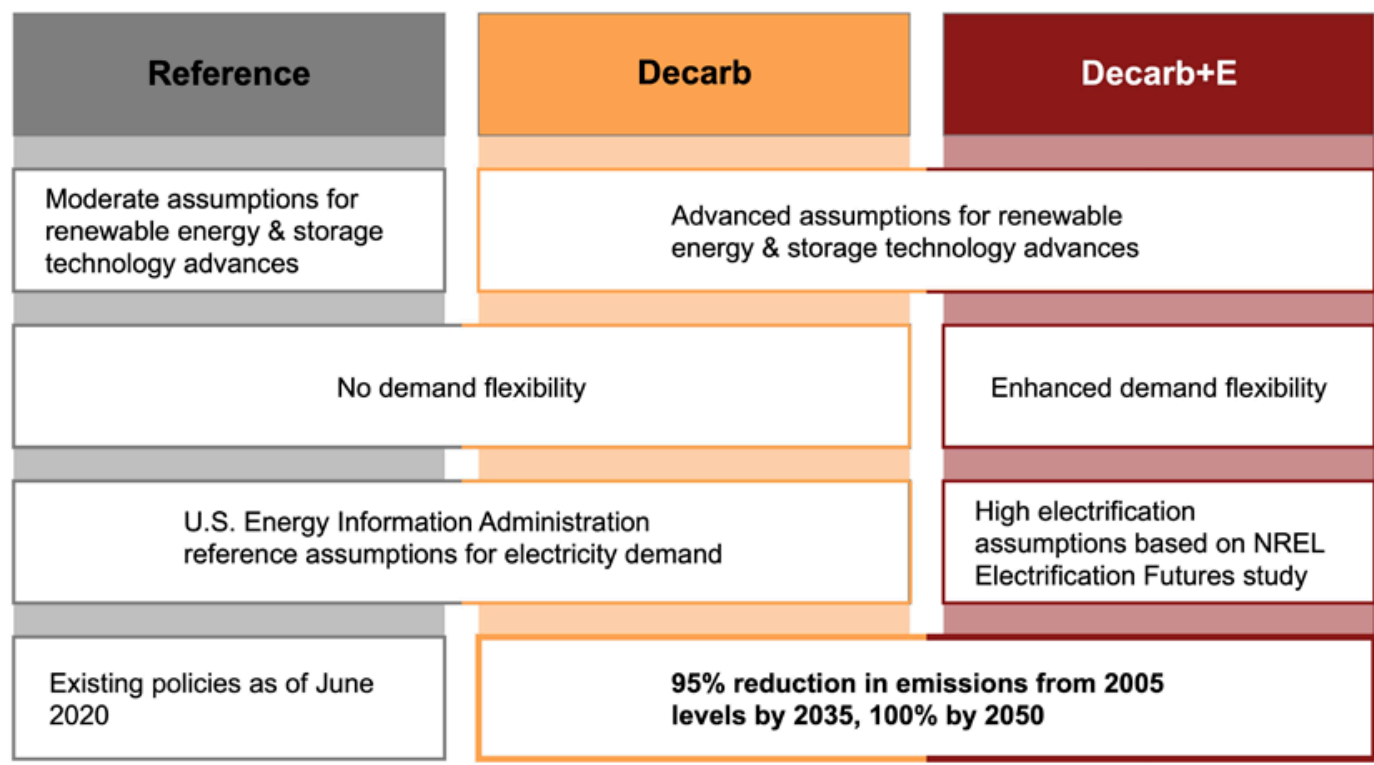

Figure 2. Framework for the Core Solar Futures Study Scenarios

Here, we compare PV and electric vehicle deployment across the three core scenarios (see Table 1). The Decarb + E scenario assumes enhanced demand flexibility and considers various opportunities for electrification, including all modes of on-road transportation, through $2050{ }^{1}$

\footnotetext{
${ }^{1}$ The Decarb+E scenario assumes end-use electrification beyond the level in the Annual Energy Outlook 2020 Reference case, reaching the level envisioned in the Electrification Futures Study (EFS) "High Electrification" scenario (Mai et al. 2018b, Murphy et al. 2021). The Decarb+E scenario also includes exogenously specified
} 
Under the Decarb+E scenario, modeled annual U.S. electricity consumption grows from 3,900 TWh in 2020 to 4,900 TWh by 2035, and to 6,700 TWh by 2050. Electrification of the transportation sector accounts for approximately half of the increased annual demand from 2020 to 2050. Compared to the Reference scenario, modeled annual transportation electricity consumption in the Decarb+E scenario is 11 times higher by 2035 and 12 times higher by 2050 . Meeting the tremendous scale of this envisioned load growth with variable renewable energy, including PV, will require transformational advancements in grid management, transmission, distribution, and other technologies. New policies, market structures, and regulations will also be needed.

Table 1. Plug-In Electric Vehicle and PV Deployment Under Solar Futures Study Core Scenarios

\begin{tabular}{|l|c|c|c|}
\hline Scenario & Reference & Decarb & Decarb+E \\
\hline 2035 PEV deployment & 13 million & 13 million & 123 million \\
\hline 2050 PEV deployment & 28 million & 28 million & 250 million \\
\hline 2035 solar PV deployment & $375 \mathrm{GW}$ & $759 \mathrm{GW}$ & $995 \mathrm{GW}$ \\
\hline 2050 solar PV deployment & $674 \mathrm{GW}$ & 1,050 & $1,570 \mathrm{GW}$ \\
\hline
\end{tabular}

Both the Decarb $+E$ scenario and the Reference scenario represent an increase over the 1.5 million PEVs in the United Sates in 2020 (U.S. EIA 2020). Under the Decarb+E scenario, the vast majority ${ }^{2}$ of LDVs, MDVs, and HDVs are electric by 2050, with the total U.S. stock reaching 123 million by 2035 and 250 million by 2050 (Table 1). Alongside this electric vehicle growth, solar capacity increases from $85 \mathrm{GW}$ in 2020 to $995 \mathrm{GW}$ in 2035 and to $1,570 \mathrm{GW}$ in 2050. In the absence of new policies under the Reference scenario, solar capacity reaches 375 GW in 2035 and $674 \mathrm{GW}$ in 2050. In contrast, under the Decarb scenario, solar capacity increases to $759 \mathrm{GW}$ and $1,055 \mathrm{GW}$ in 2035 and 2050, respectively. This implies that, for every PEV, $2.3 \mathrm{~kW}$ of new solar capacity is needed to provide zero-emissions electricity. ${ }^{3}$ The growth in electric vehicles and solar generation offers potential synergies between the two technologies, because midday solar generation can be used for vehicle charging. However, technological and deployment challenges must be overcome to realize the full potential for these two technologies to work in tandem.

flexible loads from the EFS "enhanced" flexibility case (Sun et al. 2020, Murphy et al. 2021). The amount of flexible load varies over time, constituting $17 \%$ of total load in 2050 under the Decarb $+E$ scenario.

${ }^{2}$ Under the Decarb+E scenario, $88 \%$ of light-duty cars, $81 \%$ of light-duty trucks, $94 \%$ of buses, $52 \%$ of mediumduty trucks, and $37 \%$ of heavy-duty trucks on U.S. roads in 2050 are PEVs (Mai et al. 2018).

${ }^{3}$ This estimate is based on the difference in electric vehicles and solar capacity between the Decarb and Reference demand scenarios - both specifying a decarbonization target for the power sector. The incremental solar capacity can be used to serve newly electrified demand across multiple sectors, so the attribution to PEVs is imperfect. 


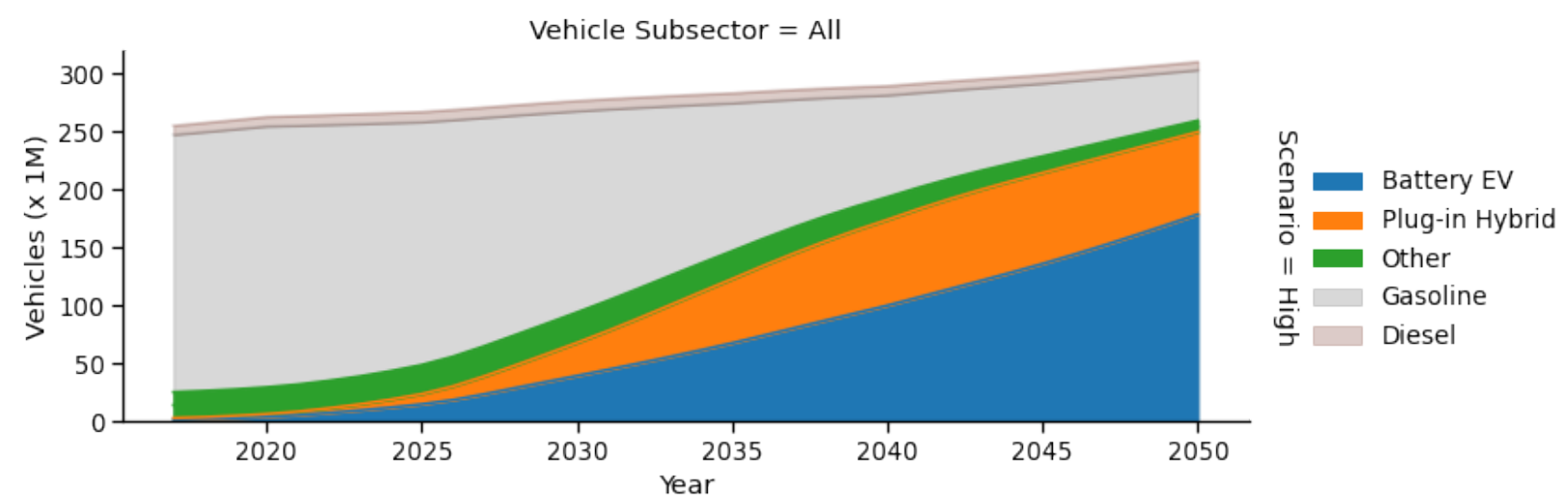

Figure 3. Modeled on-road vehicle stock from 2017-2050, by technology type, based on the Solar Futures Study Decarb+E scenario (Mai et al. 2018). "Other" includes hydrogen, natural gas, and propane fuel types.

\subsection{Synergies Between High-Penetration PV and PEVs: Technology Challenges and Opportunities}

Here, we first discuss priority PV technology advancements needed for increasing PV and electric vehicle synergies. We then identify transportation technology pathways essential to maximizing the use of PV generation for vehicle charging. In general, a limited number of pathways can be achieved through PV advancements alone; solutions across multiple technologies - including storage, communication, charging infrastructure, and vehicles - will be required.

\subsubsection{PV Technology Advancements for Electric Vehicles}

\subsubsection{On-Vehicle PV}

Vehicle-mounted PV could power electric vehicles without a grid connection, thereby mitigating potential grid impacts from vehicle charging loads. Experimental design competitions have demonstrated the technical feasibility of PV-powered vehicles traveling 1,864 miles over 4-7 days (Bridgestone 2020). However, real-world vehicles face challenges that competition vehicles do not, including the need to fit numerous passengers and cargo, haul much more weight, adhere to safety standards, and drive energy-intensive routes with many stops and accelerations. Today, three ${ }^{4}$ commercially available LDV models have on-vehicle PV, which yields an additional 1.82.2 miles traveled per day (Verger 2020). For on-vehicle PV to be economically feasible, R\&D to extend the daily PV-powered driving range is needed. A recent Toyota pilot and demonstration project resulted in on-vehicle PV that produced 4.8 times more electricity than the commercially available model (Toyota 2019), extending the daily PV-powered driving range by 8.6 miles. If this same pilot vehicle used record-breaking PV with a conversion efficiency of $47 \%$, the daily PV-powered driving range could be extended to 12 miles (Geisz et al. 2020). This is almost the entire one-way distance ( 12.7 miles) of the average U.S. car commute (National Highway Traffic Safety Administration 2017).

\footnotetext{
${ }^{4}$ These three vehicles are the 2011-2012 Fisker Karma, the 2017 Prius Prime, and the 2019 Hybrid Hyundai Sonata.
} 
Long-haul trucks could provide an even more promising application for on-vehicle PV, because they have much greater surface area. However, electric long-haul trucks are not yet commercially available and will require significant advancements to be cost-effective. Today, the most viable application of on-vehicle PV is to power the truck's heating, ventilation, and air conditioning system instead of idling the diesel engine. Preliminary evidence shows substantial fuel savings, largely because idling the diesel engine to power auxiliary loads is highly inefficient (Roeth 2020).

Today's PV technologies are generally not well suited or cost-effective for on-vehicle applications. Vehicular PV must be flexible, to allow for compatibility with aerodynamic contours, and it must have a specific power high enough to supply meaningful energy relative to a vehicle's surface area and weight. For example, crystalline-silicon PV - the most prominent PV technology today - is rigid and not well suited for on-vehicle PV in terms of weight and specific power requirements. Thin-film cadmium telluride also has limited specific power because it is spectrally mismatched for high-efficiency multijunction PV devices. Although III-V PV technologies may be technically well suited for vehicular PV systems, they are costly and have been primarily used for space applications.

All-perovskite tandems are an emerging PV technology with the potential to be highly flexible, lightweight, efficient, and affordable. With efficiencies of $25 \%$ or higher and semiconductor layers thinner than $2 \mu \mathrm{m}$, all-perovskite tandems could achieve a specific power similar to III-V technologies, but at less than $1 \%$ of the cost $(\$ 100 / \mathrm{W}$ for III-Vs vs. $\$ 0.50 / \mathrm{W}$ or less for allperovskite tandems) (Figure 4). If technical challenges can be overcome-particularly related to long-term stability - these all-perovskite tandems have the potential to be a viable option for onvehicle PV applications in the coming decades. Assuming the use of 30\%-efficient all-perovskite tandems, electric vehicle range could be extended by approximately 30 miles per day. ${ }^{5}$ Beyond efficiency and weight improvements, R\&D that increases solar conversion at suboptimal angles could increase the eligible surface area for mounting productive PV modules on vehicles.

\footnotetext{
${ }^{5}$ Key assumptions and calculations are as follows: average surface area $=7 \mathrm{~m}^{2}$, average useful area $=3.5 \mathrm{~m}$, PV module efficiency $=30 \%$, daily sun availability at 1 sun $=9.72$ hours, average PV power $=1,050 \mathrm{~W}$, average PV energy per day $=10.21 \mathrm{kWh}$, energy used per 10 miles of driving $=3.3 \mathrm{kWh}$, and range extension per day $=30.9$ miles.
} 


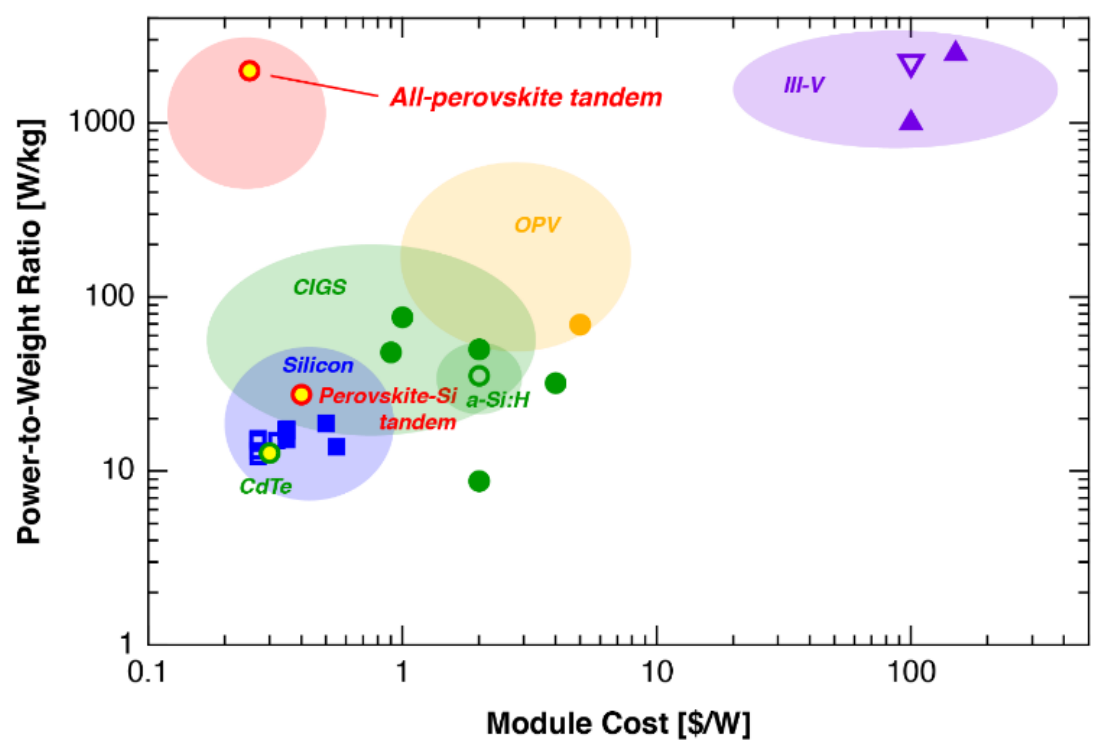

Figure 4. Estimates of specific power (power-to-weight ratio) vs. module cost for single-junction and tandem PV technologies

Source: (Reese et al. 2018) and internal NREL analysis from industry data

\subsubsection{PV Parking Canopies}

Direct vehicle charging via $\mathrm{PV}$ installed on parking canopies provides many benefits, including extension of daily driving range, reduced need for land in space-constrained areas, and shade and protection for vehicles and equipment. In addition, pairing PV parking canopies with workplace charging programs takes advantage of the fact that commuters are parked at work during the most irradiant times of day.

Data are scarce, but one study showed that, on a sunny $80^{\circ} \mathrm{F}$ day, parking in the shade all morning reduced cabin temperature by $32^{\circ} \mathrm{F}$ in a Ford Focus Electric compared with parking in the sun (Jeffers, Chaney, and Rugh 2015). This saved $1.2 \mathrm{kWh}$ from the air conditioner load needed to bring the cabin temperature down to comfortable levels over 20 minutes (average commute time), which effectively reclaims about 4 miles of range. This distance is one sixth of the average roundtrip U.S. commute. More studies must be done with more vehicles under a wider variety of conditions, but this study provides an estimate of how much electricity can be saved in areas with ample solar resources. Such a benefit would only be realized in hotter locations and months - and commute vehicle miles traveled (VMT) constitutes only about $30 \%$ of total VMT - so the impact of shading is relatively small. However, because the technology and the markets for it are mature, and because it is already being deployed, PV parking canopies represent an opportunity for PV and transportation synergies in the near term.

The balance of system costs for PV parking canopies may be higher when compared to groundmount or traditional roof-mount PV systems. While system designs may differ significantly across installations, PV parking canopies typically require taller mounting frames, a steel metal foundation, and use of heavier-gauge structural steel for column construction. Advancements to reduce the balance of system costs for PV parking canopies may help improve the economic viability of siting charging infrastructure alongside solar parking structures. 


\subsubsection{Power Electronics for Avoiding Conversion to Alternating Current}

$\mathrm{PV}$ produces direct current (DC), and car batteries charge with DC. However, all charging stations - even DC fast charging stations (DCFCs) - require alternating current (AC) to operate. DC-to-AC inverters have an approximate 13\% efficiency loss (Myers 2020). Common LDV onboard chargers have demonstrated efficiency losses of $13 \%$ when charging on Level 2 stations, and DCFCs for HDVs have demonstrated efficiency losses of around 9\% (Lohse-Busch 2012; Eudy and Jeffers 2017; 2018). Combining the efficiency losses gives an overall efficiency loss of about $26 \%$ for LDVs and $22 \%$ for HDVs. The losses could be mitigated by charging electric vehicle batteries with DC electricity directly from the PV.

The technology needed to directly couple PV to electric vehicles without converting to AC includes a DC-DC converter to ensure appropriate voltage, stationary storage, and a charger management system (Ashique 2017). Pilot projects, including projects using a DC microgrid, are demonstrating the feasibility and efficiency of this technology. However, the efficiency savings are only attainable when the sun is shining and when vehicles are plugged in and need a charge. This technology could be well suited to workplace charging situations where vehicles are parked most of the day. The impact could be increased by pairing with charge management that only uses $\mathrm{AC}$ from the grid as a last resort to provide range when the vehicle must leave at the end of the day, as reported by the vehicle driver.

\subsubsection{Multi-Technology Advancements for Electric Vehicles}

Here, we first examine the Solar Futures Study Decarb+E scenario to illustrate the importance of managed and coordinated charging for maximizing the use of PV electricity in vehicle charging. We then describe the advancements needed for managed and coordinated charging. Finally, we provide an overview of end-of-life solutions for increasing synergies between PV and electric vehicles.

\subsubsection{Managed and Coordinated Charging to Maximize PV Use for Electric Vehicle Charging}

Increased electric vehicle charging can result in uneven increases in electricity demand if appropriate policies, rate designs, specific programs, and charging infrastructure at daytime parking locations are not in place. Typical light-duty charging behavior increases peak demand, as many vehicle owners return home to charge in the evening. For grids with high PV penetration, the need to balance supply and demand becomes especially pronounced in the evening, as the solar resource diminishes during this evening peak. Concentrating high power demand over a short period may pose operational challenges for load-serving entities and can exacerbate the need for generators to quickly ramp up energy production when PV generation falls. This steep production ramp may increase grid emissions by causing higher-emitting peaker plants to serve load (Burlig et al. 2020).

The Decarb+E scenario assumes $51 \%$ of transportation load is flexible in 2050 , with flexibility provided through vehicle owner participation in demand response programs, increased availability of managed and coordinated charging, and other measures. Figure 5 illustrates modeled 2050 hourly load and PV generation for the Decarb+E scenario and compares load without transportation flexibility to load with transportation flexibility. The figure depicts 2050 demand across the entire United States during the week when the highest net load occurs for the 
year (November $\left.14^{\text {th }}\right)$. The net load, or total demand less all variable renewable generation, indicates the remaining demand that must be met by dispatchable resources. Large net-load ramps, shown in solid blue in Figure 5, are particularly challenging for grid systems to meet. Transportation flexibility helps reduce the steepness and magnitude of these net load ramps, even though it may potentially increase the overall demand peak for a particular day. In the Decarb+E scenario, absent flexible transportation demand, the net load differential between when the lowest net demand occurs $(2$ p.m. $)$ and when the peak net demand occurs $(6$ p.m. $)$ is more than $800 \mathrm{GW}$. When transportation flexibility is added, the magnitude and steepness of the ramp decline, with the magnitude decreasing from $814 \mathrm{GW}$ to $567 \mathrm{GW}$ and the average ramp rate between 2 p.m. and 6 p.m. decreasing from $203 \mathrm{MW} / \mathrm{hr}$ to $125 \mathrm{MW} / \mathrm{hr}$.

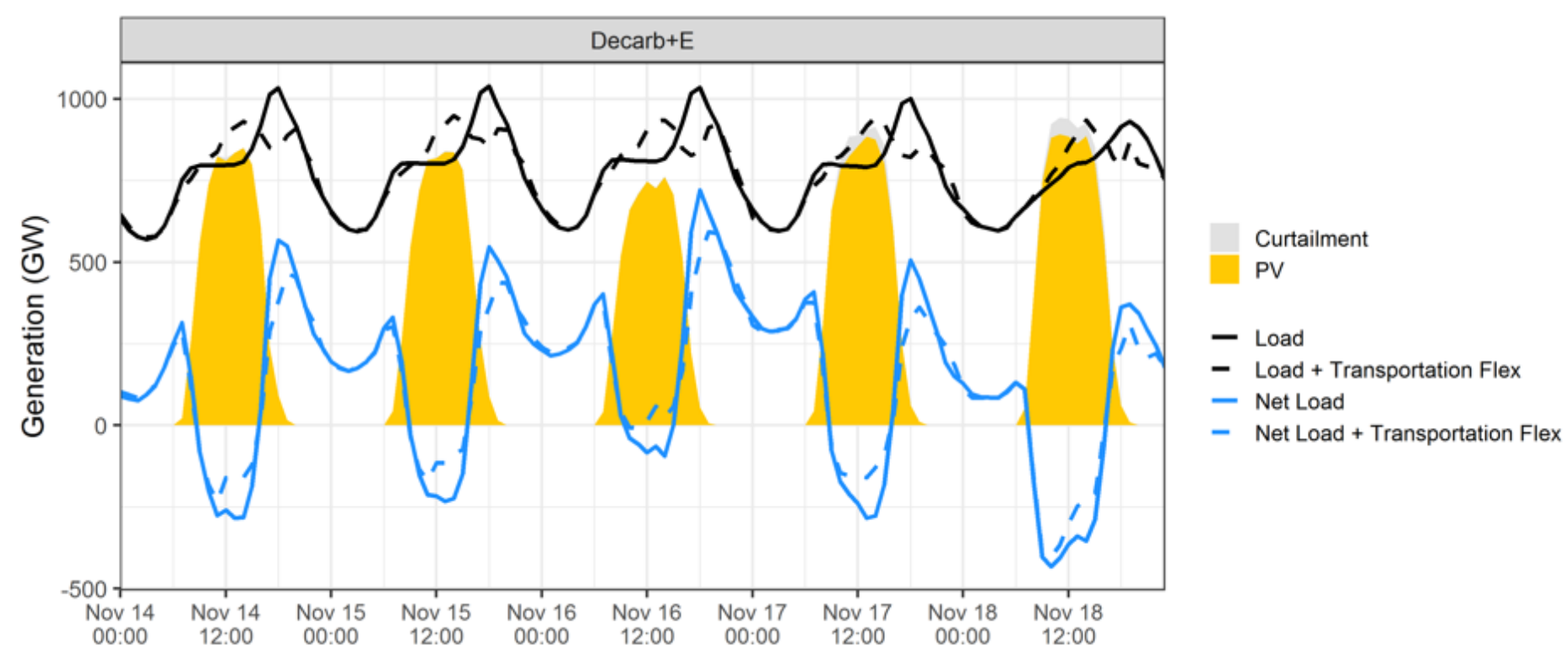

Figure 5. Modeled 2050 hourly load and PV generation for the Solar Futures Study Decarb+E scenario

Managed and coordinated charging distributes charging events more evenly across off-peak hours or times of peak renewable energy production, thereby minimizing grid stress and maintaining grid stability. Managed and coordinated charging is one of the most important strategies for realizing the potential benefits and synergies of electric vehicle and PV deployment. It is also essential for advancing future V2G approaches that use the bidirectional capabilities of vehicle batteries to store excess PV generation and supply the grid with electricity and ancillary services. Today, various software and other technological solutions for managed and coordinated charging are under development or in early phases of deployment. Although a comprehensive evaluation of managed and coordinated charging options is outside the scope of this report, Table 2 summarizes example strategies. 
Table 2. Examples of Managed and Coordinated Charging Strategies for PEVs

\begin{tabular}{|l|l|}
\hline $\begin{array}{l}\text { Managed/Coordinated } \\
\text { Charging Strategy }\end{array}$ & Description \\
\hline Delayed charging & $\begin{array}{l}\text { Timer and software allow electric vehicles to be charged at a } \\
\text { predetermined time to stagger charging and shift load. }\end{array}$ \\
\hline Regulation of power draw & $\begin{array}{l}\text { Peak demand is reduced by managing and reducing the amount of } \\
\text { instantaneous power each electric vehicle draws. }\end{array}$ \\
\hline Disabled charging & $\begin{array}{l}\text { Peak demand is reduced and shifted by eliminating the ability of select } \\
\text { electric vehicles to charge during certain times. }\end{array}$ \\
\hline Price signals & $\begin{array}{l}\text { Price signals, such as time-of-use (TOU) pricing, reduce costs for vehicle } \\
\text { owners to charge at times of low demand or high PV production. }\end{array}$ \\
\hline
\end{tabular}

\subsubsection{Communications Protocols for Managed and Coordinated Electric Vehicle Charging}

Today, the simplest technologies for shifting vehicle charging loads are charge timers that owners use in conjunction with demand charge data and time-varying pricing schemes, such as time-of-use (TOU) pricing. Charge timers are mature and commonly available, but they can result in a "rebound peak" that increases peak load when many vehicle owners charge concurrently at the start of a specified timeframe (Myers 2020). "Smart chargers," or vehicles enabled with communication capabilities, can adjust charging current, timing, and duration based on signals from the utility. Second-generation technologies are enabling utilities to better align charge timing with grid needs. As of 2019, there were 38 utility-run managed charging pilot and demonstration projects (Myers 2020). Alternatively, charging can be actively controlled by facility managers, aggregators, or network service providers (NSPs). NSPs specialize in coordinating information about charging events, and $80 \%$ of NSPs are already equipped with managed charging capabilities (Myers 2020).

Utilities can directly communicate with and control charging through an NSP, the charging equipment, and the vehicle. Most (71\%) of utility-run pilot projects have targeted the charging equipment (Myers 2020), although direct communication between the utility and the vehicle has been shown to increase renewable energy use (Julia Pyper 2020). The hardware and software needed for managed charging are largely developed and available. However, standardized communications protocols are needed. Today, few utilities include electric vehicle load as part of a managed technology portfolio, and they use several different open communications standards. A standardized language that enables the utility to coordinate charging as part of a demand response program could support the alignment of charging with PV production and provide beneficial grid support as PEVs increase. Some form of compensation or direct customer benefit might be needed to animate participation in managed charging, either through a one-time participation payment or a recurring payment.

\subsubsection{Vehicle Technologies to Increase Charge Speed and Flexibility}

Increasing charge speed and flexibility enables vehicle demand to more accurately match PV supply, thus reducing the need for intermediate electricity storage. When paired with managed charging, vehicle batteries with a greater range of charge rates provide greater load flexibility. The batteries of most contemporary PEVs in the United States can accommodate EVSE power 
ranging from $1.4 \mathrm{~kW}$ (Level 1) to $50 \mathrm{~kW}$ (standard DCFC) while still achieving the warrantied, minimum battery life of eight years (or 100,000 miles) required by federal law. ${ }^{6}$ Greater charging speeds can further increase flexibility, but charging current batteries at substantially greater speeds reduces battery life, owing to the deleterious effects of dissipated heat and lithium plating (Oberhaus 2020).

There is currently a major $\mathrm{R} \& \mathrm{D}$ effort to increase the maximum charge rate of batteries to 350 $\mathrm{kW}$ and higher through new battery chemistries, configurations, thermal management, and charging algorithms (Tomaszewska et al 2019). When batteries that can charge at $350 \mathrm{~kW}$ become commercially available, infrastructure and charging locations will already be established to charge at that speed. Electrify America, which has plans to install 3,500 DCFCs by December 2021, is installing DCFCs capable of charging up to $350 \mathrm{~kW}$ near highways (Tubman 2018). To date, 294 of these 350-kW chargers have been installed (U.S. Department of Energy 2021a). These fast chargers can ratchet down the power output based on the capabilities of individual cars and the real-time battery state of charge. Future fast chargers may also adjust power output based on the production of connected PV, which would improve matching of vehicle charging loads with PV production.

Although rapid progress is being made through high-power battery R\&D programs, significant improvements to grid infrastructure that enable high-power charging will be needed to maximize the impact of battery advancements (especially if numerous chargers are co-located). Today, over $80 \%$ of charging events occur at homes where high-power charging is unavailable, and a significant portion of non-residential charging occurs at grid locations that cannot support highpower charging (U.S. Department of Energy 2020a).

\subsubsection{Battery Technologies to Withstand Extensive V2G Applications}

V2G technologies may enable higher levels of PV penetration by using electric vehicle batteries to store excess PV generation and then discharging that stored electricity to the grid when needed. The additional hardware required for $\mathrm{V} 2 \mathrm{G}$ includes bidirectional inverters that allow the DC electricity in the battery to flow back to the grid as AC. This technology is available today, though battery degradation, and the resulting need for more frequent battery replacement, poses a significant barrier to V2G cost-effectiveness (Richardson 2013; Wang et al. 2016). With today's commercially available technologies, providing extensive $\mathrm{V} 2 \mathrm{G}$ services ${ }^{7}$ would require purchasing an oversized battery or shortening battery longevity, both of which erode the economic viability of V2G. Incremental improvements to lithium-ion or lithium-iron phosphate batteries could enable an appropriately sized battery to be used for V2G while maintaining full battery life. The Million Mile Battery R\&D Initiative recently announced industry development of a battery that can withstand 1.24 million miles of travel — an eightfold increase in the distance covered under current vehicle battery warranties. This new battery costs $10 \%$ more than vehicle batteries commercially available today, but it can withstand significantly more charge cycles (Bloomberg 2020). Continued industry advancement toward more durable battery technologies

\footnotetext{
${ }^{6}$ For a typical driver, battery life often extends well beyond the warranty period of eight years required by federal law.

${ }^{7}$ For the purposes of this report, we rely on Wang et al. (2016) and define "extensive" as more than two hours per day.
} 
increases the feasibility of V2G applications and the potential to increase PV use for transportation. For a more in-depth discussion of battery technology R\&D and storage deployment, see the Solar Futures Study main report (DOE 2021). It should be noted that beyond the V2G hardware and battery technologies mentioned in this section, additional regulations will likely be needed to enable V2G (California Public Utilities Commission 2020).

\subsubsection{End-of-Life Opportunities for Increasing PV and Electric Vehicle Synergies}

\section{Secondary Use of Electric Vehicle Batteries as Stationary Batteries}

Today, when the capacity of an electric vehicle battery declines to $80 \%$ of its original capacity, the performance is insufficient for continued vehicle use, but may still be adequate for certain stationary storage applications (Mathews et al. 2020). Repurposing electric vehicle batteries for stationary storage could offer many benefits, including reduced capital costs for PV and storage projects. Second-life batteries could offer a 30\%-70\% cost savings compared to new batteries in applications that require less frequent battery cycling (around 100-300 cycles per year) (Engle, Hertzke, and Siccardo 2019). Ultimately, with the proliferation of electric vehicles, the supply of repurposed vehicle batteries for stationary applications could exceed $200 \mathrm{GWh} /$ year by 2030 (Engle, Hertzke, and Siccardo 2019). This supply of repurposed batteries could be made readily available for projects focused on energy arbitrage, in which PV energy stored during periods of peak production is used later in the day, thus enhancing grid flexibility. There is also a growing body of research indicating that reuse of vehicle batteries for large-scale stationary storage applications may be more feasible than previously thought. For example, consider the economics of a 2.5-MW PV array paired with a new lithium-ion battery system vs. an array paired with a repurposed electric vehicle battery with $80 \%$ of original capacity. Research has shown that the new battery system does not yield a favorable net return on investment; however, this same PV array paired with a repurposed electric vehicle battery can be operational for a decade or longer and is profitable when the cost of repurposed batteries falls below $60 \%$ of the original cost (Mathews et al. 2020). Lastly, second-life batteries could potentially offset $19 \%$ of the initial battery purchase cost through provision of grid services (Debnath, Ahmad, and Habibi 2014).

To date, secondary use of electric vehicle batteries as stationary batteries has been demonstrated for smaller-scale projects, although implementing repurposed batteries for grid-scale applications will require $\mathrm{R} \& \mathrm{D}$ to overcome certain barriers. These barriers include the high cost of battery refurbishment due to variation in battery pack designs across manufactures, a lack of performance and quality standards for second-life batteries, and the need for vehicle battery designs that enable greater battery reuse. Although some automakers-including Nissan and Renault - have formalized plans and partnerships for reusing electric vehicle batteries in stationary applications, considerable $\mathrm{R} \& \mathrm{D}$ will be needed to fully realize the market potential for PV paired with second-life batteries.

\section{Recycling PV Modules and Electric Vehicle Batteries}

PV modules contain toxic materials, such as lead, alongside valuable and recyclable components, including silver and glass. These attributes have inspired an increasing number of countries to restrict dumping of PV modules into landfills and promote recycling programs. Owing to the ultra-high capacity of silicon, "Generation 3" batteries are currently being developed to use silicon as the anode. Because crystalline-silicon PV modules contain approximately $5 \%$ silicon, there may be opportunities to recover PV silicon for use in vehicle batteries (Vekony 2020). This 
approach could reduce the energy intensity of silicon production for Generation 3 batteries while providing silicon that meets the high purity requirements of battery anodes. A pathway for recovering silicon from PV that is suitable for Generation 3 batteries has been proposed and proven, but further R\&D is needed (Eshraghi et al. 2020).

\subsection{Non-Hardware Barriers to Co-Deployment of High-Penetration PV and Electric Vehicles}

Today, 45 states and the District of Columbia have some form of incentive or policy support for PEVs (U.S. Department of Energy 2021b). Many measures are similar to those currently offered for PV, including tax credits, rebates, and deployment goals. Achieving the Solar Futures Study scenarios will require market and regulatory advancements for PV, electric vehicles, and charging infrastructure. In this section, we discuss priority non-hardware barriers and potential approaches for overcoming them. Table 3 provides a summary.

Table 3. Barriers to Co-Deployment of High-Penetration PV and Electric Vehicles, With Mitigation Opportunities

\begin{tabular}{|l|l|}
\hline Deployment Barriers & Opportunities \\
\hline $\begin{array}{l}\text { Lack of time-varying electricity } \\
\text { rate structures and managed } \\
\text { charging }\end{array}$ & $\begin{array}{l}\text { Utility implementation of time-varying rate structures could } \\
\text { encourage greater vehicle charging during midday PV production. }\end{array}$ \\
\hline Lack of workplace charging & $\begin{array}{l}\text { Increased availability of workplace charging could support greater } \\
\text { use of PV electricity for charging, and managed charging } \\
\text { strategies could reduce employer utility bills as EVSE deployment } \\
\text { grows. }\end{array}$ \\
\hline $\begin{array}{l}\text { Lack of affordable and accessible } \\
\text { and PEVs for all communities }\end{array}$ & $\begin{array}{l}\text { Opportunities include income-qualified incentives and rebates for } \\
\text { purchasing PEVs, new business models and programs that } \\
\text { bundle EVSE with community solar projects, and siting EVSE in } \\
\text { underserved communities. }\end{array}$ \\
\hline $\begin{array}{l}\text { Lack of consistent and efficient } \\
\text { permitting and interconnection } \\
\text { requirements and processes }\end{array}$ & $\begin{array}{l}\text { Development and implementation of best practices for vehicle } \\
\text { charging and PV permitting and interconnection is needed to } \\
\text { rapidly scale these technologies. }\end{array}$ \\
\hline
\end{tabular}

\subsubsection{Expanding Time-Varying Electricity Rate Structures}

Time-varying electricity rate structures change the price of electricity based on when it is consumed and can influence vehicle owners and workplace charging programs to shift charging to midday, when PV energy is most abundant. Time-varying rates have potential to be especially effective in supporting grid stability when integrated with managed and coordinated charging. Specifically, staggered charging and other strategies to distribute charging events more evenly across a specified timeframe could help utilities avoid unintentional TOU timer peaks (see Section 2.2.2.2). Approximately half of U.S. investor-owned utilities offer some form of residential time-varying rate to encourage load reduction during peak demand periods (Hledik, Faruqui, and Warner 2018), and over 100 utilities have implemented time-varying rates specific to electric vehicles (Muratori, Kontou, and Eichman 2019).

The peak to off-peak ratio describes the difference in pricing between the highest-priced peak periods and the lowest-priced off-peak periods. Some time-varying rate structures have 
intermediate or shoulder periods when the price is set between the peak and off-peak rates. Electric vehicle loads are generally more flexible than other loads (Cappers, Hans, and Scheer 2015) and thus can be highly responsive to time-varying rates. A preliminary San Diego Gas and Electric (SDG\&E) case study tested three rates with on/off peak price ratios ranging from approximately 2:1 to 6:1 (Figure 6). Across the three rates, $78 \%-92 \%$ of PEV charging shifted to off-peak times (Whited, Allison, and Wilson 2018). ${ }^{8}$ Also pictured in Figure 6 is Xcel Colorado's TOU rate, which applies to all residential loads rather than electric vehicle loads only. The Xcel rate offers longer shoulders and a shorter peak period. As PV and electric vehicles continue to scale, broad implementation of time-varying and other innovative rate structures may be needed to maximize the use of PV electricity for charging and encourage charging behavior that supports grid operations.

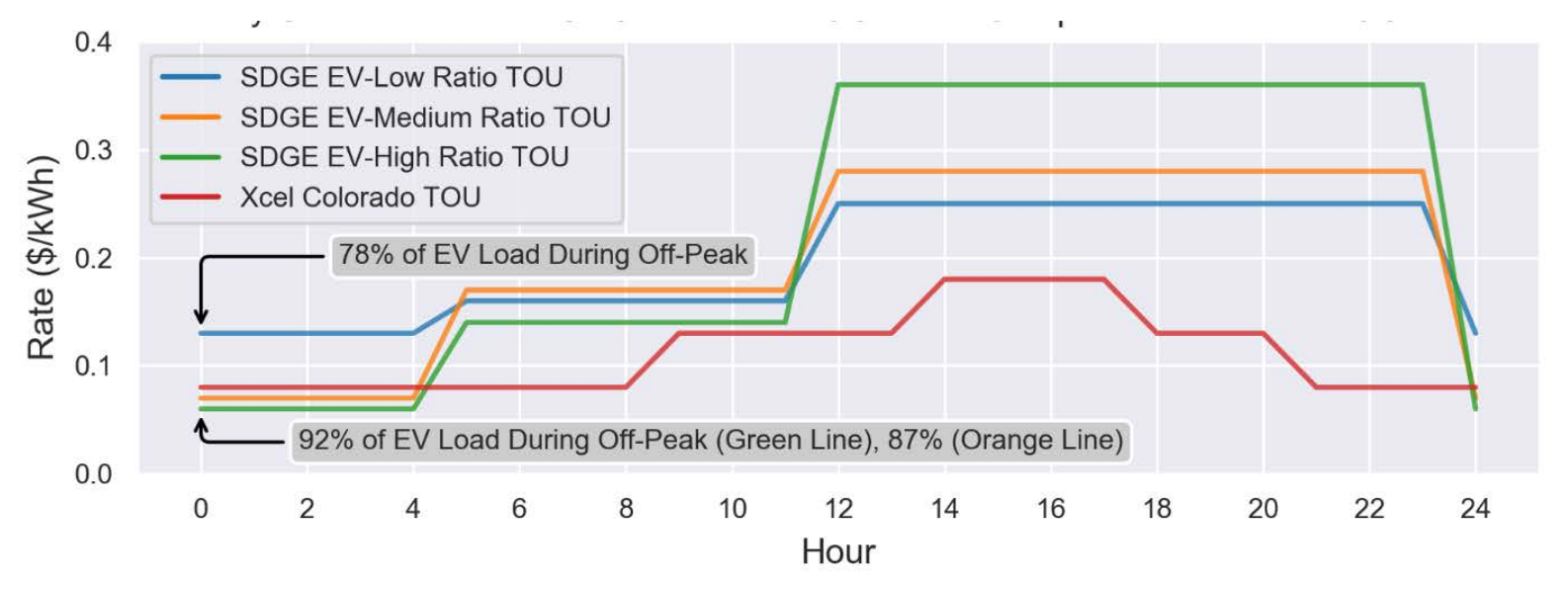

Figure 6. Daily summer prices for SDG\&E pilot PEV TOU rates and Xcel Colorado TOU rate

\subsubsection{Increasing Workplace Charging Access and Availability}

Workplace charging provides employees with convenient access to charging stations, and is an important driver of electric vehicle adoption (Slowik and Lutsey 2018). Workplace charging also enables greater daytime charging with carbon-free PV electricity. Today, workplace charging availability lags behind the anticipated growth in electric vehicles. Expanding workplace charging will likely be needed as commuting with electric vehicles becomes commonplace.

Assuming employees commonly spend 8 hours per day at the workplace, sufficient availability of onsite Level 2 charging could extend vehicle driving ranges by over 200 miles and significantly reduce range anxiety for a typical commuter (Borlaug et al. 2020). Despite these benefits, employers considering workplace charging often cite increased utility costs as a concern. Charge-control and power-management systems can be used to reduce overall utility costs by optimizing vehicle charging and maximizing charging during times of the day when solar power is most plentiful. Research conducted at the National Renewable Energy Laboratory (NREL) campus has demonstrated that using charge-control systems to decrease charging during peak demand periods can decrease annualized average electricity costs by $50 \%$ (Jun and Meintz

\footnotetext{
${ }^{8}$ Pilots by Pacific Gas \& Electric (PG\&E) and Southern California Edison similarly found that customers on PEV TOU rates shifted $93 \%$ and $88 \%$ of PEV charging to off peak, respectively.
} 
2018). Although these findings are specific to Xcel's utility rate structures and NREL's building loads, they illustrate the effectiveness of managed workplace charging to reduce employer utility bills.

\subsubsection{Overcoming Barriers to Equitable Adoption}

Low- to moderate-income households and communities of color have adopted PV at a lower rate. Between 2010 and 2018, approximately $75 \%$ of new residential PV was installed in households earning more than $120 \%$ of the area median income (Barbose et al. 2020). When controlling for income, census tracts with majority Black and Hispanic populations exhibit 30\% and $69 \%$ less rooftop PV, respectively (Sunter, Castellanos, and Kammen 2019). Electric vehicles demonstrate a similar trend. In California, which has more than half the country's electric vehicles, only $14 \%$ of electric vehicle owners have an annual income of less than $\$ 50,000$, while $56 \%$ of owners earn more than $\$ 100,000$ per year (Muehlegger and Rapson 2018). In 2018, only $12 \%$ of electric vehicle purchases were made by Hispanic and African American individuals combined, yet this group constitutes $45.9 \%$ of California's population (Muehlegger and Rapson 2018; U.S. Census Bureau 2019). Demographic data for FCEVs is limited given the relatively small size of the U.S. market, and further research related to equitable adoption will be needed as the technology becomes more widespread.

Addressing the historically unequal adoption of $\mathrm{PV}$ and clean transportation technologies across income and demographic groups will require new policy and regulatory approaches. Emerging solutions include income-qualified incentives and rebates for PEV and FCEV purchases. New business models and programs that bundle charging infrastructure with community solar projects have the potential to increase access to emissions-free charging. Community-shared charging coupled with PV can also help accommodate larger charging loads. Expanding vehicle electrification beyond single-occupancy, owner-occupied vehicles to transit vehicles and rideshare fleets can enable broader use of clean transportation options. Finally, charging infrastructure and PV must be sited in underserved communities, including at multifamily housing locations and in public spaces, to increase opportunities for vehicle charging and charging with PV (Baldwin, Myers, and O'Boyle 2020). For a more detailed discussion of equity considerations for solar, see the Solar Futures Study main report (DOE 2021).

\subsubsection{Implementing Best Practices for Permitting and Interconnection}

Local jurisdiction building permits and utility interconnection agreements are required for $\mathrm{PV}$ systems and electric vehicle charging stations in the United States. These requirements are designed to ensure the safety of installations, but navigating the complexity and variation in requirements across jurisdictions and utilities can add to the cost and time of project completion (Ardani et al 2012, Nelder and Rogers 2019). While ongoing research and other efforts have helped identify and advance cost reduction pathways for solar, detailed permitting and interconnection costs for electric vehicle charging infrastructure are not well understood. New research to benchmark non-hardware costs and identify cost reduction pathways for charging stations is needed, though preliminary research suggests strong parallels between the soft costs of charging infrastructure and solar (Nelder and Rogers 2019). For example, delays in obtaining utility interconnection approval, easements, and building permits have been identified as causes of increased charging infrastructure project costs or cancellation, especially for public DCFC locations (Nelder and Rogers 2019). 
Continued development and widespread adoption of permitting and interconnection best practices can help reduce the regulatory barriers to PV and electric vehicle deployment. Best practices for PV have been developed and are in varying stages of adoption, whereas best practices for charging stations are more nascent. Ongoing NREL research suggests that measures to streamline PV permitting and interconnection, such as online platforms, utility hosting capacity maps, and automated processes, can reduce approval times and yield cost savings (Ardani 2015, O'Shaughnessy et al. 2020). For vehicle charging stations, interconnection processes and best practices differ for utility owned infrastructure and third-party owned infrastructure (Smart Electric Power Alliance 2020). For third-party owned systems, developers have cited the following emergent best practices: providing greater visibility into available hosting capacity, increasing communication between the developer and the utility, and maintaining a single point of contact at the utility (Nelder and Rogers 2019). Measures to increase the flow of information between utilities and developers may be especially important for DCFC installations coupled with storage, a relatively new technology configuration that lacks precedent and a standard interconnection approach (Nelder and Rogers 2020). Strategies for improving charging infrastructure permitting may be similar to strategies used for PV, and may include the development of detailed checklists to clarify requirements, guidebooks that provide detail on optimal permitting processes, designation programs that recognize local jurisdictions for adopting best practices, and harmonization of requirements within and across states. California, the most mature market in the United States for clean energy and transportation technologies, has implemented statewide efforts to improve permitting for PV and charging stations under Assembly Bill 2188 and 1236, respectively. Similar actions will likely be necessary across the United States as PV and electric vehicle adoption accelerates. 


\section{Opportunities and Challenges Related to PV and Hydrogen Vehicle Synergies}

Fuel cell technology uses the chemical energy of hydrogen or other fuels to produce electricity for applications such as stationary power and transportation. For the transportation sector, hydrogen proton exchange membrane (PEM) FCEVs could provide many benefits, including fast refueling, long range, high payload, and zero tailpipe emissions. When using hydrogen produced via water electrolysis powered by renewable energy, FCEVs have near-zero life cycle emissions. This form of "green hydrogen" is becoming increasingly cost-competitive as the price of wind and PV electricity continues to decline.

Today, U.S. FCEV applications include forklifts $(>40,000)$, passenger cars $(\sim 10,000)$, and buses $(>60)$ (Satyapal 2021). Recent analyses indicate a potential future FCEV market equilibrium of at least 22\% market share (3.9 million vehicles) for MDVs and HDVs (Ruth et al. 2020; Elgowainy et al. 2020). Industry reports show further opportunities for hydrogen in rail (up to 20\% market share) (Hydrogen Council 2017), aviation (up to 25\% market share) (Hydrogen Council 2021), and e-fuels production to help decarbonize the remaining MDV/HDV, marine, aviation, and rail segments. In particular, the MDV/HDV sector is poised for considerable nearterm growth (2025-2030), as organizations electrify their fleets. This sector may present opportunities for additional PV deployment to meet rising demand for green electrolytic hydrogen. To date, FCEV market adoption has been limited by high upfront vehicle prices, limited refueling infrastructure, and hydrogen prices that are roughly four times higher than gasoline prices (CARB 2020). However, low-cost electricity from PV and wind is expected to help make green hydrogen prices competitive with fossil-fuel derived hydrogen (which currently dominates the market) as soon as 2030, and potentially cheaper by 2050 (Bloomberg 2019).

Hydrogen has been safely used by industrial, chemical, and vehicle markets across the world, and significant R\&D has been focused on improving hydrogen safety in recent decades. The safety of FCEVs is demonstrated by the maximum safety rating (five stars) awarded to the 2018 Hyundai NEXO (Euro NCAP 2018). As the hydrogen vehicle transition occurs, continued focus on safety in hydrogen vehicle design, operation, and infrastructure is necessary for this technology's viability.

In this section, we rely on current literature to envision a future with high penetration of PV and hydrogen on-road vehicles. We identify the key technology and deployment barriers to realizing this high-penetration future, and synthesize the potential R\&D areas needed to overcome the barriers identified. We also draw on interviews with FCEV, transportation, and grid experts to identify factors that may enable or inhibit synergistic PV and FCEV deployment in the United States.

\subsection{Exploring the Future of PV and Hydrogen Vehicles}

Although the United States has more FCEVs than any other country, with $\sim 10,000$ in use as of June 2021 (Satyapal 2021), FCEVs represent a nominal share of the nation's more than 270 million registered passenger vehicles (U.S. Department of Transportation 2019). Less than 4\% of the 11.4 MMT of hydrogen consumed annually in the United States is dedicated to transportation end uses, compared to $57 \%$ for petroleum refining and $38 \%$ for methanol and ammonia 
production (Hydrogen Council 2019). As the market for hydrogen vehicles and associated fueling infrastructure matures, there will be significant opportunities for FCEV and PV growth.

Near-term growth opportunities for PV-based hydrogen FCEVs include commercial vehicles (Hunter, Penev, Reznicek, Lustbader, et al. 2021; Nikola Motor 2019; Adler 2020) and heavy off-road vehicles (Homann 2020), because hydrogen storage cost and weight are lower and refueling rates are faster than PEVs. These attributes can give FCEVs longer ranges, faster refueling, and higher payload capacities than PEVs, and allow FCEV technology to complement PEV technology by serving market segments that value these attributes.

Analysis for the U.S. Department of Energy's (DOE's) H2@Scale initiative estimates a future market equilibrium of approximately 3.9 million medium- and heavy-duty FCEVs (Ruth et al. 2020; Elgowainy et al. 2020). This would result in $5 \mathrm{MMT} / \mathrm{yr}$ of hydrogen economic potential for a low-cost electrolysis scenario in a mature on-road transportation market (Ruth et al. 2020). Assuming that $100 \%$ of this hydrogen is created from low-temperature electrolysis with an electricity use of about $51 \mathrm{kWh} / \mathrm{kg}$ (NREL 2019), and assuming an 80\% capacity factor to account for oversizing the electrolyzer to provide grid services (Wang et al. 2018), about $36 \mathrm{GW}$ of electrolyzers would need to be built. PV could meet a significant portion of this new electricity load. Assuming PV (with a capacity factor of 25\%) is used to meet the new electricity demand for hydrogen production, an additional nearly $120 \mathrm{GW}$ of PV capacity could be installed by 2050 . The electricity load and PV deployment would increase further if FCEVs were adopted across other transportation markets, such as non-road and off-road vehicle segments, including ports (yard tractors, container handlers, forklifts), heavy machinery, agriculture, and mining. The electricity load and PV deployment would also increase further if this hydrogen were liquefied and transported to vehicle refueling stations, or if hydrogen was exported outside of the United States to decarbonize vehicles in other countries.

Another recent study evaluated three different future vehicle markets: all BEVs, all hydrogen FCEVs, and an equal market share between BEVs and FCEVs (Kiani 2020). For each scenario, the optimal California grid and vehicle population were co-simulated to identify opportunities for the grid to support vehicle electrification and for vehicles to support high penetration of renewable energy, including PV. Although this study focuses on California, it highlights four important conclusions about how FCEVs support a high-PV grid:

- Peak load can be decreased significantly.

- PV curtailment and electricity transmission and distribution losses can be reduced.

- Total energy cost to the consumer can be reduced.

- PV energy price can be increased.

For the 50/50 BEV/FCEV scenario, peak load can be decreased (by about 30\% in 2045 for the California Independent System Operator, compared to a 100\% BEV scenario), because electrolyzers that create hydrogen to fuel FCEVs can operate flexibly during the day and store hydrogen until it is needed for refueling. When electrolyzers act as a flexible load, they preferentially operate when PV production is high and electricity prices and grid emissions are low. This increases PV capacity factors and reduces PV curtailment, and it provides an effective price floor for PV generation, as the electrolyzers provide a reliable source of demand. The study also shows that the higher PV electricity price is offset by lower costs for electricity 
infrastructure, such as transmission and distribution, resulting in a lower total energy cost to consumers in the 50/50 BEV/FCEV scenario compared to the $100 \% \mathrm{BEV}$ and $100 \% \mathrm{FCEV}$ scenarios. $^{9}$

The full value proposition of widespread, low-cost PV electricity being converted into hydrogen for use in other sectors is difficult to quantify, owing to the complex, integrated, and crosssectoral modeling required. Kiani (2020) demonstrates the synergistic opportunity of flexible electrolysis to simultaneously support PV integration into the grid while providing low-cost, green hydrogen for long-duration energy storage, transportation, and industry. Improved analysis tools that couple multiple sectors are needed to fully quantify the value proposition of hydrogen electrolysis for supporting high PV penetrations. Although this is a mathematically complex task, it could be completed in the near term.

Other studies evaluate the impact of FCEV deployment and how using electrolyzers for hydrogen production can support variable renewable energy integration in the near term (Wang et al. 2018). These studies show that flexible electrolyzers can reduce PV curtailment, reduce grid operation costs, and support PV integration (Zhang et al. 2020). However, these synergistic opportunities for PV and FCEVs still have R\&D, demonstration, and deployment challenges to overcome.

\subsection{Synergies Between High-Penetration PV and FCEVs: Technology Challenges and Opportunities}

Achieving a significant increase in PV and FCEVs will require substantial technological advancements in hydrogen refueling infrastructure and FCEVs. Although there are opportunities for solar R\&D to advance PV and FCEV synergies, they are more limited. Here, we provide an overview of electrolysis for hydrogen production, and then discuss the priority advancements needed for refueling infrastructure and FCEVs.

\subsubsection{Hydrogen Production and Use of PV}

Hydrogen can be produced at large, centralized locations before being distributed to vehicle refueling stations, or it can be produced at a smaller scale at refueling stations (Figure 7). Centralized hydrogen production is covered in the Solar Futures Study main report (DOE 2021). Here, we focus on hydrogen production as it integrates with the transportation sector.

\footnotetext{
${ }^{9}$ Converting electricity to hydrogen and back to electricity using an on-board vehicle fuel cell has a roundtrip efficiency of about 35\%, significantly lower than using the electricity in a BEV. Increasing PV deployment or improving PV utilization can compensate for this efficiency loss. Kiani (2020) shows that the efficiency losses are primarily offset through improved PV utilization, with minimal increases in PV buildout.
} 


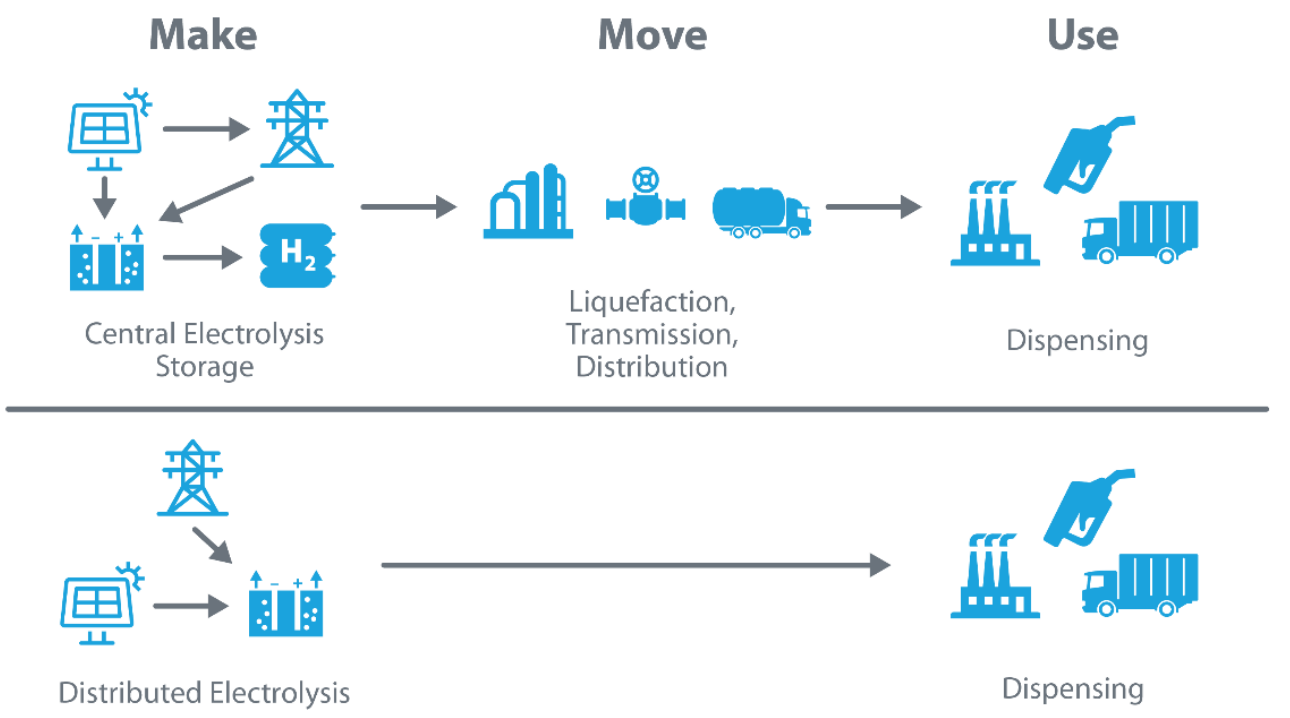

Figure 7. Overview of centralized vs. distributed hydrogen infrastructure for refueling FCEVs

Low-cost, renewable (green) hydrogen is critical to accelerating FCEV adoption. Currently, the transportation market is dominated by "gray" hydrogen, which is created from large, centralized plants using steam-methane reforming (SMR) of natural gas. Although current LDV hydrogen costs (about $\$ 16 / \mathrm{kg}$ ) are nearly four times the cost of gasoline on a useful energy basis (CARB 2020), ${ }^{10}$ hydrogen produced for MDVs and HDVs is much more competitive with diesel (Eudy 2019). This is because about $88 \%$ of the LDV hydrogen cost is attributable to the small scale of the transmission, distribution, and dispensing network (Connelly et al. 2019). The levelized cost of SMR hydrogen production is about $\$ 2 / \mathrm{kg}$, indicating that two things must happen to achieve low-cost dispensed green hydrogen: production must switch from SMR to a green hydrogen production process, and the levelized cost of hydrogen transmission, distribution, and dispensing must be decreased substantially. PV can help address both these challenges.

PV can facilitate the switch from SMR to green hydrogen. The leading process for green hydrogen production is low-temperature PEM electrolysis. Current electrolyzer technology requires about $55 \mathrm{kWh} / \mathrm{kg}$ of electricity (NREL 2019), so hydrogen cost strongly correlates with electricity price. Accounting for only the marginal electrolyzer electricity use, achieving \$2$\$ 3 / \mathrm{kg}$ requires an electricity price of $\$ 36-\$ 54 / \mathrm{MWh}$. The input electricity price must be lower than this to recover the capital and other operating expenses while maintaining a competitive hydrogen price. PV could solve this challenge by providing electricity to large-scale electrolyzers for $\$ 24-\$ 28 /$ MWh by 2030 and $\$ 15-\$ 17 /$ MWh by 2050 (Bloomberg 2019).

PV could also reduce the high cost of hydrogen transmission, distribution, and dispensing. Hydrogen can be transported as a gas or converted to a liquid through liquefaction before being distributed. Gaseous hydrogen is typically distributed in tube trailer trucks for small quantities (less than about 1 tonne/day) and short distances (less than about 200 miles) or via pipeline for

\footnotetext{
${ }^{10}$ FCEV fuel economy is about twice as high as ICE vehicle fuel economy, which is captured in this calculation (Joseck and Sutherland 2015).
} 
large quantities (greater than about 200 tonne/day) (Hunter et al. Forthcoming). In intermediate quantities, liquefied hydrogen is typically the most cost-competitive, but it requires an energyintensive liquefaction step (requiring about $8 \mathrm{kWh} / \mathrm{kg}$ ) (Argonne National Laboratory 2020). The small scale of current hydrogen supply chains increases delivered hydrogen costs. As hydrogen supply chains increase in scale, coupling liquefaction with plentiful PV electricity could better utilize PV assets while decreasing hydrogen delivery costs.

\subsubsection{Use of Otherwise-Curtailed Electricity}

Hydrogen from low-temperature PEM electrolysis is energy intensive (requiring about 55 $\mathrm{kWh} / \mathrm{kg}$ ), and liquefying hydrogen for delivery requires additional energy (about $8 \mathrm{kWh} / \mathrm{kg}$ ). To provide cost-competitive green hydrogen for transportation, the electricity cost for electrolysis and liquefaction (plus other compression, cooling, and so forth in the hydrogen supply chain) must be below about \$40/MWh. Electrolyzers' need for low-cost, green electricity, combined with their flexibility when coupled with storage, makes them ideal for supporting high PV penetrations. Hydrogen production is synergistic with high PV penetrations because it improves PV utilization (Kiani 2020; Ruth et al. 2020) and hedges against wholesale market price volatility (Eichman et al. 2020). Using otherwise-curtailed PV electricity could be a near-term opportunity for hydrogen production across centralized and distributed supply-chain designs. Furthermore, there is potential to coordinate the timing of electrolysis with PEV managed charging strategies (see Section 2.2.2.1) to better align electricity supply and demand.

\subsubsection{MDV/HDV Hydrogen Refueling Stations: Modularity of Components and PV}

As MDV and HDV fleets begin to adopt hydrogen fuel cell technology, public stations must be able to start small and grow as FCEV adoption increases. Although private stations purchased by and dedicated to one company may be used for initial market demonstration, wide rollout of medium- and heavy-duty FCEVs would require public refueling infrastructure. When coupled, a modular system design for both the refueling station and PV system would allow these stations to optimize capital utilization while supporting a growing FCEV fleet. Additionally, adding PV in a modular way could help defer grid infrastructure upgrade costs, depending on the amount and location of energy required on the electricity grid. Refueling station network optimization can also be used to hedge against low refueling station and PV capital utilization. Current hydrogen refueling stations are designed for LDVs, which already have high capital costs and low utilization ( Jean and Achtelik 2019; Saur, Gilleon, and Sprik 2021), so R\&D that enables modularity and incremental development with low costs would help facilitate hydrogen refueling station expansion and enable distributed PV rollout.

\subsubsection{MDV/HDV Hydrogen Refueling Stations}

As hydrogen refueling stations are designed and built, potential electricity demand charges must be understood and mitigated. Assuming a typical diesel truck station in a mature market has a throughput of about 800,000 gal/month (Bulk Transporter 2008) and all trucks are converted to FCEVs, the station would have a hydrogen throughput of about 20 tonne/day -2.5 times larger than the stations Nikola has proposed in early market installations (Nikola Motor 2020) - after accounting for the fuel economy improvement from diesel trucks to FCEVs (Hunter, Penev, Reznicek, Lustbader, et al. 2021). Assuming approximately $57 \mathrm{kWh} / \mathrm{kg}$ are required to produce 
and compress the hydrogen, ${ }^{11}$ this would result in an estimated average power demand of about 50 MW. Thus, coupling PV and storage may avoid demand charges from high power consumption, either from onsite hydrogen production with electrolysis or instantaneous high compressor loads. A gaseous hydrogen compressor of about $1 \mathrm{MW}$ would be needed (Argonne National Laboratory 2020) for the current Class 8 tractor DOE target refueling rate of about 10 $\mathrm{kg} / \mathrm{min}$, equivalent to a refueling time of about 6 minutes (Marcinkoski 2019). Although a recent analysis explores how PV can be integrated with hydrogen production via electrolysis (Eichman et al. 2020), refueling station process dynamics have not yet been evaluated in a behind-themeter optimization framework. Additionally, these large-scale refueling stations must be demonstrated and validated in integrated energy systems. Liquefaction may provide an alternative to this high refueling station energy requirement, because liquefaction would move the energy requirement upstream to a centralized liquefaction plant, which could be coupled with bulk PV power. Continued development of analytic tools for behind-the-meter optimization, assessment of tradeoffs between liquefaction and gaseous hydrogen supply chains, demonstration of refueling stations in integrated energy systems, and advanced control algorithms could help the demand-charge management challenge.

Over the long term, as regional and long-distance HDVs convert to hydrogen fuel cell powertrains, public hydrogen refueling stations will likely be needed along major interstates. Although the optimal design of a U.S. hydrogen supply chain for MDVs and HDVs has not been evaluated in detail, companies have indicated interest in producing hydrogen at refueling stations on dedicated travel routes (Nikola Motor 2020). This approach has the advantage of needing to move water, and some fraction of the necessary electricity, rather than hydrogen. Using the same station assumptions described above, and including some additional assumptions, ${ }^{12}$ this equates to about $100 \mathrm{MW}$ of PV_requiring over 800 acres of land - to support a truck stop. This is nearly four times the size of the largest U.S. truck stop ("Iowa 80" 2020). Such stations would likely be limited to remote locations or highways that have sufficient land available, unless breakthrough footprint reductions can be achieved.

\subsubsection{Breakthrough R\&D on Liquefaction and Storage}

Producing hydrogen at refueling stations may not be economically attractive in regions where low-cost PV electricity cannot be coupled with electrolyzers. Alternatives to producing hydrogen locally include producing it centrally and liquefying it for distribution, or moving it via gaseous pipelines. Existing liquefaction plants are large (about 130 tonne/day of hydrogen throughput) and very difficult to scale down. Breakthrough liquefaction techniques that enable smaller-scale liquefaction may allow an earlier transition toward a liquefied hydrogen distribution system while maintaining low hydrogen costs. Liquefaction breakthroughs would also support PV integration by providing another potentially flexible load for the grid to use in addition to flexible electrolyzers.

\footnotetext{
${ }^{11}$ The energy intensity of $57 \mathrm{kWh} / \mathrm{kg}$ includes $55 \mathrm{kWh} / \mathrm{kg}$ for electrolysis plus about $1.5 \mathrm{kWh} / \mathrm{kg}$ for compression and $0.5 \mathrm{kWh} / \mathrm{kg}$ for other loads.

${ }^{12}$ Additional assumptions include 50\% of electricity coming from PV (50\% from the grid) (Eichman et al. 2020), a 25\% PV capacity factor (National Renewable Energy Lab 2020), and 4.1 acres/GWh/yr (Ong et al. 2013).
} 
Similarly, storing compressed hydrogen can be expensive at small to medium scales (about $\$ 30 / \mathrm{kWh}-\mathrm{AC}$ ) and requires a large footprint (Argonne National Laboratory 2020). Breakthrough hydrogen storage, through materials-based approaches such as metal hydrides and adsorbents that reduce both the cost of hydrogen storage and the geographic footprint, could further accelerate the deployment of hydrogen refueling stations and the simultaneous rollout of distributed PV at these stations.

\subsubsection{Dedicated Hydrogen Transmission and Delivery Infrastructure}

About $88 \%$ of the current light-duty hydrogen cost comes from the small scale of the transmission, distribution, and dispensing network. Over time, the growing FCEV fleet and hydrogen demand may tip investment toward the creation of a dedicated hydrogen supply-chain infrastructure. However, because pipelines are very capital intensive, dedicated hydrogen pipelines are very costly at low volumes, and are difficult to justify given uncertain future demand. As the cost of producing hydrogen decreases through integrated PV and electrolysis, the hydrogen demand may achieve a scale sufficient for low-cost hydrogen transmission and delivery via conventional pipelines. Additionally, R\&D to support smaller, higher-pressure pipelines should be evaluated as a way to reduce high upfront capital costs while still building dedicated hydrogen infrastructure (Penev, Zuboy, and Hunter 2019). As dedicated hydrogen infrastructure is achieved, a low levelized cost transmission and distribution network will reduce the hydrogen price for FCEVs, further catalyze FCEV adoption, and accelerate the widespread integration of PV into the electricity grid. Finally, R\&D to analyze, demonstrate, and evaluate hydrogen blending in existing natural gas pipelines could provide a transitional step toward a dedicated hydrogen pipeline network.

\subsubsection{Fuel Cell V2G}

Like BEVs, FCEVs can act as a flexible generator and provide electricity back to the grid (Robledo et al. 2018; Qian et al. 2020). As adoption of FCEVs increases, this flexible resource will become larger and more valuable. FCEVs have a total specific energy $(\mathrm{kWh} / \mathrm{kg})$ that is roughly four times higher than that of BEVs, which may make them highly suitable for V2G applications. Additionally, FCEVs - particularly in the MDV/HDV segment, which has higher potential market penetration - can be charged with green hydrogen created via low-cost PV. These vehicles may be discharged in the evening or overnight, creating an economic incentive for adoption, especially if hydrogen fueling times are kept low and consistent with current diesel fueling times (Marcinkoski 2019). Finally, if these vehicles were automated and could operate overnight, there may be additional incentive for them to provide V2G services in the evening, during peak load times, and operate overnight to complete required freight movements.

However, analogous to durability challenges for batteries, V2G applications for FCEVs entail the tradeoff of using the high capital cost fuel cell system to produce grid electricity. Fuel cell system improvements - such as using advanced membrane materials, increasing platinum group metal catalyst load, improving corrosion-resistant bipolar plate materials, and improving system control strategies to reduce fuel cell degradation - are needed to attain durability sufficient to meet vehicle lifetime requirements and provide additional grid services. Finally, implementing V2G in a grid at scale must still be researched and demonstrated. This could support PV deployment by 2035, but the relative impact of the energy storage is expected to be modest and dependent on the scale of FCEV adoption. 


\subsection{Deployment Challenges and Opportunities for PV and FCEVs}

Significant adoption and integration of PV and FCEVs by 2035 and 2050 will require market and regulatory advancements for PV, FCEVs, and hydrogen refueling infrastructure. In this section, we discuss priority deployment barriers and potential approaches for overcoming them by 2035 and 2050. Table 4 provides a summary.

Table 4. Deployment Barriers to High-Penetration PV and FCEVs, With Mitigation Opportunities

\begin{tabular}{|l|l|}
\hline Deployment Barriers & Opportunities \\
\hline $\begin{array}{l}\text { Electrolyzer access to } \\
\text { wholesale power markets }\end{array}$ & $\begin{array}{l}\text { Providing electrolyzers access to wholesale markets provides flexible } \\
\text { load for utilities to manage the grid while reducing the cost of hydrogen } \\
\text { for FCEVs. }\end{array}$ \\
\hline $\begin{array}{l}\text { Power-to-gas } \\
\text { implementation }\end{array}$ & $\begin{array}{l}\text { Needs include classifying power-to-gas as an energy storage technology } \\
\text { and developing national hydrogen injection and blending standards. } \\
\text { Enabling utilities to store excess solar energy in chemical form will } \\
\text { support PV rollout and could also provide hydrogen at low cost for } \\
\text { FCEVs. }\end{array}$ \\
\hline $\begin{array}{l}\text { Public awareness and } \\
\text { acceptance }\end{array}$ & $\begin{array}{l}\text { Increased public awareness and acceptance of hydrogen's safety and } \\
\text { environmental benefits will help adoption of FCEVs and supporting } \\
\text { refueling infrastructure. }\end{array}$ \\
\hline $\begin{array}{l}\text { Public support for early- } \\
\text { stage infrastructure } \\
\text { investment }\end{array}$ & $\begin{array}{l}\text { Public support for capital-intensive hydrogen refueling infrastructure } \\
\text { could accelerate station development and FCEV adoption. }\end{array}$ \\
\hline $\begin{array}{l}\text { Electrolyzer, fuel cell, and } \\
\text { on-board hydrogen storage } \\
\text { component costs }\end{array}$ & $\begin{array}{l}\text { R\&D to decrease electrolyzer capital cost can help reduce the cost of } \\
\text { hydrogen production. Decreasing fuel cell and on-board hydrogen } \\
\text { storage costs will accelerate FCEV adoption. }\end{array}$ \\
\hline
\end{tabular}

\subsubsection{Electrolyzer Access to Wholesale Markets}

A recent NREL analysis for PG\&E evaluated integrated PV and hydrogen production with electrolysis for six market participant configurations in California. The results show that if flexible loads such as electrolyzers had wholesale market access for all hours of the day, breakeven hydrogen costs could decrease by $53 \%-61 \%$ to $\$ 2.6-\$ 3.1 / \mathrm{kg}$, close to competitive with gray hydrogen. However, this configuration is not currently proven in California, because the programs that allow devices to access wholesale markets (direct access, NGR, PDR) are not open, nor do they give flexible loads sufficient exposure to wholesale markets (Eichman et al. 2020). Providing electrolyzers or other flexible loads access to wholesale markets could spur increased PV deployment and improved utilization while decreasing hydrogen production costs. Low green hydrogen prices are a key driver of FCEV adoption, and allowing hydrogen producers to access wholesale power markets could further accelerate PV and FCEV adoption.

\subsubsection{Power-to-Gas Implementation}

Storing plentiful, low-cost PV energy for use in the electricity sector or other energy sectors improves PV's value proposition. Converting PV electricity into a chemical carrier such as hydrogen could provide long-duration energy storage for the grid or inputs to other markets, such as the gas and transportation markets (Hunter, Penev, Reznicek, Eichman, et al. 2021). (See the Solar Futures Study main report (DOE 2021) for additional discussion regarding long duration energy storage. If hydrogen is blended into the natural gas system, it could be used for heating, 
or potentially separated for use in FCEVs (Melaina, Antonia, and Penev 2013). However, there are two deployment barriers specific to blending into the natural gas system. First, current regulations do not consider chemical blending into the natural gas system as a form of energy storage, and second, national hydrogen injection and blending standards do not currently exist (Hydrogen Council 2019). Addressing these deployment barriers could provide a path to more PV installations and utilization, as well as low-cost green hydrogen for the transportation market.

\subsubsection{Public Acceptance and Awareness}

Public awareness and acceptance of hydrogen is crucial for the adoption, deployment, and scaleup of FCEVs and supporting hydrogen infrastructure (Ricci, Bellaby, and Flynn 2008). Educational campaigns and other outreach measures to increase public awareness of hydrogen's safety and potential environmental benefits - as well as the cost and capabilities of the technology, especially when coupled with PV - are critical to developing a favorable public perception of hydrogen (Edwards, Font-Palma, and Howe 2021; Iribarren et al. 2016). As consumer adoption and awareness of FCEVs and hydrogen increase, it is imperative to maintain a consistent focus on safety to reinforce the public perception that hydrogen technologies are safe.

\subsubsection{Public Support for Early-Stage Infrastructure Investment}

Hydrogen refueling infrastructure is currently limited to just over 40 stations, primarily in California (Satyapal 2020; CARB 2020). Hydrogen refueling stations are more capital intensive than PEV charging infrastructure, making them higher-risk investments, especially when FCEV adoption is limited due to high vehicle purchase prices. Increased public support for refueling station rollout can help reduce investment risks, accelerate FCEV adoption, and increase the utilization of PV.

\subsubsection{Electrolyzer, Fuel Cell, and On-Board Hydrogen Storage Costs}

Electrolyzer capital costs (currently $\sim \$ 1,500 / \mathrm{kW}$ ) (Hunter, Penev, Reznicek, Eichman, et al. 2021 ) can contribute $\$ 1-\$ 3 / \mathrm{kg}$ to the levelized cost of hydrogen production (Eichman et al. 2020). R\&D to reduce this capital cost is underway (Satyapal 2021), and future estimates based on learning through deployment indicate that capital costs of $\sim \$ 180 / \mathrm{kW}$ could be achieved, reducing the levelized cost of hydrogen production to $\$ 2.4 / \mathrm{kg}$ in grids with high PV deployment (Hunter, Penev, Reznicek, Eichman, et al. 2021), comparable to fossil-fuel derived hydrogen. In addition to reducing the hydrogen cost for FCEVs, R\&D to reduce the fuel cell system and onboard hydrogen storage system is also critical for decreasing the upfront purchase price of commercial vehicles with fuel cell powertrains and making the total cost of ownership competitive with diesel trucks (Hunter, Penev, Reznicek, Lustbader, et al. 2021). 


\section{Opportunities and Challenges for PV and Rail, Air, and Maritime Applications}

Rail, air, and maritime applications, although they consume less total energy than on-road applications (Figure 8), present unique PV-pairing opportunities and face unique challenges. These modes of transport are generally larger and need to travel farther between refueling than their on-road counterparts. Trains and ships are much more energy efficient than cars and trucks for transporting goods, whereas planes are much less efficient. For passenger transport, trains are over twice as energy efficient as planes, but both are roughly as efficient as their on-road counterparts (buses and LDVs, respectively). Energy use from U.S. air travel is projected to increase $120 \%$ between 2020 and 2050 , whereas rail is projected to increase only $9 \%$ and maritime is estimated to decrease by 1\% (U.S. Energy Information Administration 2021).

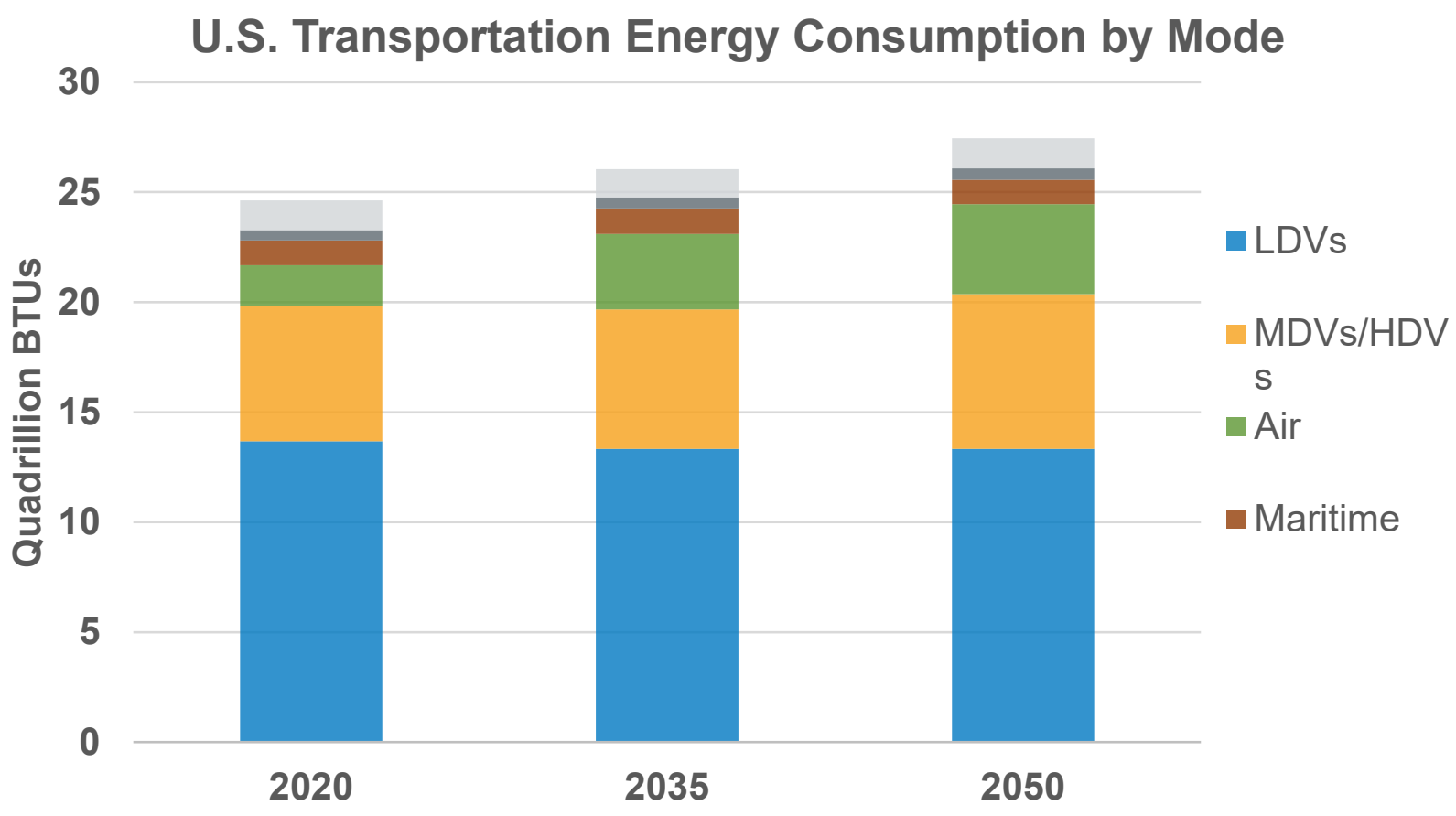

Figure 8. U.S. transportation sector energy use in 2020, 2035, and 2050 (U.S. Energy Information Administration 2021)

A rigorous market adoption analysis of deep decarbonization in the rail, air, and maritime sectors has not been completed. However, economic and market-fit analyses have been completed for many of these segments. The appendix outlines a simplistic analysis of what deep decarbonization could look like across these sectors and the resulting net-zero-carbon fuel types that could be used. PV could play a vital role in decarbonizing these sectors, because the netzero-carbon fuels include further electrification (air) as well as hydrogen production and use, either as fuel (rail, air) or as a precursor for other fuels used in these segments (ammonia, methanol, synthetic jet fuel). The Solar Futures Study main report (DOE 2021) quantifies the amount of PV that could be used for deep decarbonization of the rail, air, and maritime sectors to be $\sim 400 \mathrm{GW}$ by 2050 under this simplified market adoption scenario. 


\subsection{Rail}

Rail is currently the second-largest modal share of freight transportation in ton-miles, but is the lowest consumer of freight transportation energy compared to on-road trucks, waterways, and pipelines (Hoffrichter 2019). There are three primary segments of rail: freight, passenger, and switcher. Freight locomotives are primarily used to move freight, passenger locomotives are used to move passengers along routes, and switchers are used for moving railroad cars inside a rail yard. Owing to their different use cases, each locomotive segment has slightly different power and energy requirements (Ahluwalia, Papadias, and Wang 2020).

Freight locomotives have the highest power requirement (about 4,400 horse power) and operate at higher notch levels (closer to peak power rating). This makes them highly suitable for diesel engines, which have flatter efficiency vs. rated power curves (Ahluwalia, Papadias, and Wang 2020). Thus, the optimal use of low-cost PV may be to create liquid fuels that can drop into existing diesel freight locomotives in the near term.

Passenger locomotives have a slightly lower power requirement (about 3,000 hp) and operate at lower speeds with more frequent stops (Ahluwalia, Papadias, and Wang 2020). This gives electrified powertrains, such as overhead catenary or fuel cell electric powertrains, potential to be more economically attractive. Electric rail catenary lines are well established, with electricity providing approximately a third of the energy used by rail globally (Nunno 2018). However, less than $1 \%$ of U.S. railroad track is electrified, representing a large potential opportunity for electrification. Catenary lines are economically preferable to battery-powered locomotives because expensive batteries can be foregone, and the infrastructure buildout is much less than required for roadway catenary systems. Adding more high-voltage catenary lines over rail also offers the opportunity to connect widely distributed PV systems. Making these connections would increase the consistency of PV output, because the PV catchment area would span most local weather patterns (Nunno 2018). Expanded catenary lines may also establish transmission from some areas with large PV potential and inexpensive land to those without these characteristics. Hydrogen fuel cell electric powertrains may be economically superior to diesel powertrains because of the higher fuel cell efficiency (Ahluwalia, Papadias, and Wang 2020). However, the environmental and economic benefit of hydrogen fuel cell passenger locomotives can only be achieved if green, low-cost hydrogen is available. PV coupled with flexible electrolysis may provide a viable pathway for green hydrogen to be used in passenger locomotives.

Switcher locomotives may be easier to electrify using catenary lines or fuel cell electric powertrains, owing to their limited distances of travel and lower-power duty cycles (Ahluwalia, Papadias, and Wang 2020). However, there are challenges with durability and mechanical/materials robustness needed for this rugged application (Duve 2019). Thus, net-zerocarbon biofuels may provide alternative fuels for this segment.

The primary hurdle to overhead catenary electric rail in the United States has traditionally been access to capital, even though operating costs are much lower for electric trains than for diesel. Solutions worth investigating include low-interest loans and savings-backed financing arrangements similar to Energy Savings Performance Contracts. Furthermore, using the catenary lines as transmission could bring a new value stream and more partners to the table. In-depth economic analysis of the investment is beyond the scope of this report, but utility or government 
partners might cover enough of the upfront infrastructure costs to make investment in electric trains worthwhile. For fuel cell electric locomotives, barriers include high upfront capital cost in the near term, high hydrogen prices (unless low-cost green hydrogen can be used), space requirements for hydrogen storage, fuel cell durability challenges, and hydrogen refueling station design and placement optimization.

\subsection{Air Transport}

Air transport can be broken down into segments based on aircraft and flight patterns of varying lengths, and each segment can then be matched with decarbonization options. Commuter and regional flights with less than $\sim 80$ passengers and traveling for less than $\sim 1,000 \mathrm{~km}$ may be suitable for direct electrification with batteries. These flights represent up to $\sim 15 \%$ of revenue passenger kilometers (Schäfer et al. 2019). Short-range $(\sim 2,000-\mathrm{km})$ flights with $\sim 165$ passengers represent nearly $25 \%$ of global aviation $\mathrm{CO}_{2}$ emissions, and may be most suitable for hydrogen combustion in turbine engines. Longer-range aircraft with more passengers may be most suitable for synthetic hydrocarbon fuels created with $\mathrm{CO}_{2}$ and $\mathrm{PV}$-based electrolytic hydrogen (Hydrogen Council 2021). Low-cost PV would be critical for charging the electric aircraft and generating hydrogen for hydrogen turbines, or for producing net-zero synthetic hydrocarbons.

PV offers additional synergies with electrified planes, ground vehicles, and buildings through the hubs of air transportation: airports. Electric reliability is so valuable to airports that many are considering or planning to create their own microgrids (Baskas 2019). PV can be a suitable electricity source for most airport microgrids, and airports have substantial land and roof space for PV. PV is also one of the safest electricity sources at airports, where equipment height, reflectivity, and effect on radio waves is of utmost concern (National Renewable Energy Lab 2017; National Academy of Sciences 2011). However, the timing of airport energy use does not align perfectly with PV production. This could be mitigated via smart charging and V2G technologies (i.e., drawing on passenger PEVs and electrified ground support equipment), or by electrolyzers coupled with hydrogen storage and fuel cells for electrification.

One limitation to airport PV is glare, which could temporarily hinder pilots or air traffic controllers. A 2016 survey showed that $9 \%$ of pilots had experienced glare, and of those, $4 \%$ classified it as a "significant nuisance" (Barrett 2016). However, proper siting and planning, supported by available resources, can minimize this already rare occurrence. The Solar Glare Hazard Analysis Tool (SGHAT) was developed to predict potential glare from proposed projects (Ho 2013). Glare is a larger concern for CSP, because its mirrors, bellows, and shields are much more reflective than PV modules. A list of best practices has been developed to minimize risks to pilots (National Academy of Sciences 2011).

\subsubsection{Electric Airplanes}

Most energy used in aviation goes toward powering aircraft. The primary barrier to electric planes is the relatively low energy density of batteries, and the consequently heavy weight of batteries powerful enough to enable flight (Schäfer et al. 2019). Figure 9 shows the energy densities of fuels and batteries. Most solutions to this barrier include reducing the range, lightening the airplane, and improving aircraft efficiency. These solutions are numerous and 
incremental; the remainder of this section focuses on aircraft technologies that are less incremental.

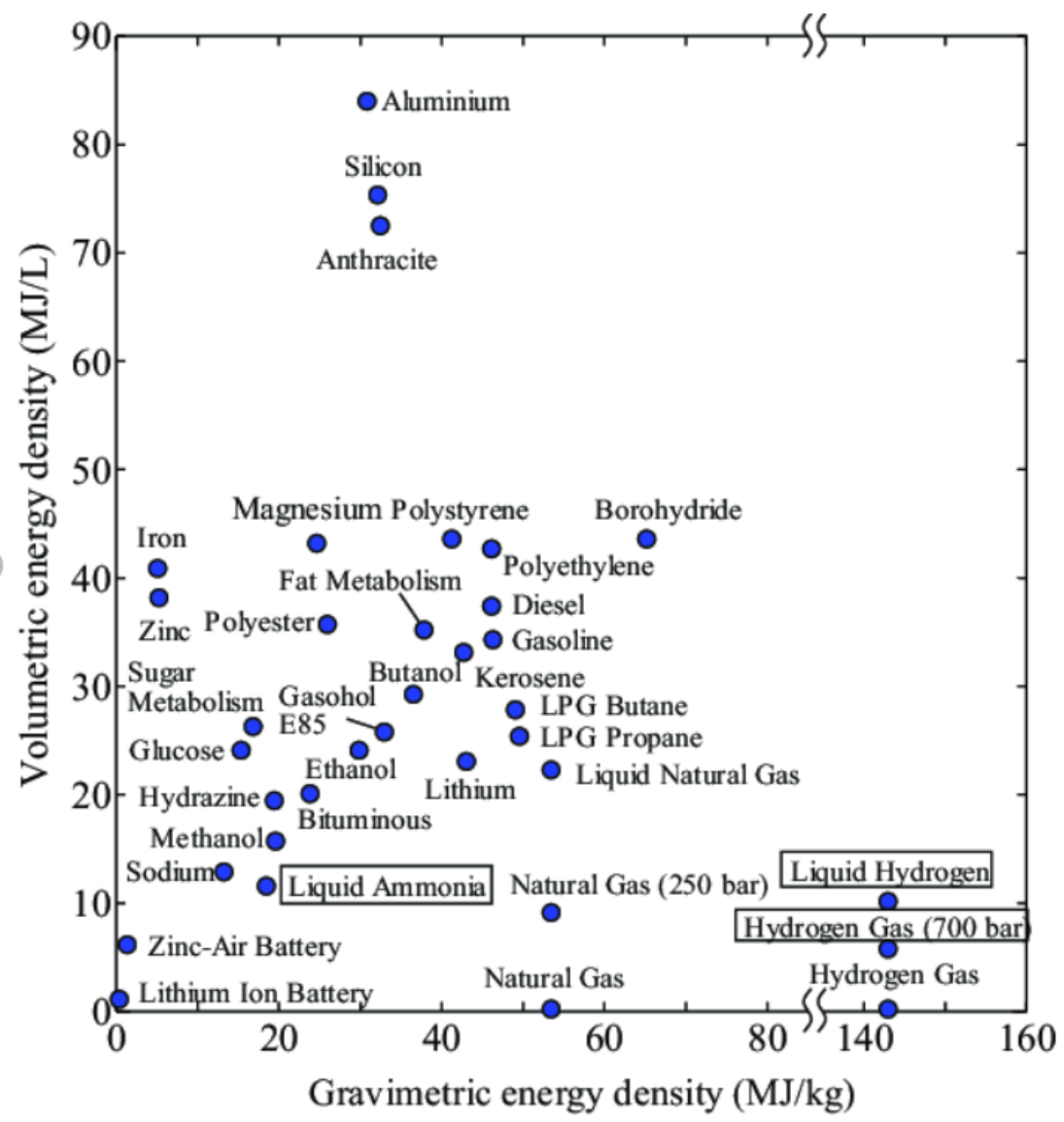

Figure 9. Volumetric and gravimetric energy density of fuels (Kobayahsi et al. 2018)

\subsubsection{Airplane Battery Swap}

Another barrier to battery-powered airplanes is the time necessary to recharge between flights. Gate time at a major airport, usually wrapped into landing fees, is very expensive. Minimizing gate time would require extremely fast/powerful chargers that would greatly add to the airport's demand charges. Furthermore, adding such load would likely require substantial infrastructure upgrades at the airport. One promising solution is a battery swap station for aircraft that enables aircraft to quickly swap batteries during their usual gate time. Spent batteries could then charge at managed speeds over a longer period. Pairing charging stations with variable PV production would enable flexible use of PV generation. Electric Delivery Drones and Vertical Takeoff and Landing (VTOL) Vehicles

Electric delivery drones have become a promising technology to complete the "last mile" of package delivery. R\&D efforts are well funded by high-profile operations, including Amazon's Prime Air and Google's Wing, as well as UPS and Uber Eats. Prime Air first delivered a package via drone in 2016, but it seems to have been surpassed by Wing, which overcame substantial regulatory hurdles to become the first company to gain approval for drone delivery by numerous governments, including the U.S. Federal Aviation Administration (Levin 2019). By doing so, 
Wing has made it easier for other companies to gain similar approval. Wing continues to lead the way in drone delivery, and now has pilot delivery services in Helsinki, two towns in Australia, and Christiansburg, Virginia (Malay-Mail 2019). Payload capacity seems to be the largest limitation to drone delivery; no drones offered at a price point suitable for delivery services can carry more than $10 \mathrm{~kg}$ (Butler 2021)

Electric vertical takeoff and landing (eVTOL) vehicles share many attributes with drones, but they carry a larger payload and are already carrying humans (Bryson Taylor 2020). Morgan Stanley Research estimates that the eVTOL market will be worth $\$ 1.5$ trillion by 2040 (Morgan Stanley 2019). Projections suggest that markets will develop first for military applications and package delivery, which both have fewer regulatory hurdles than passenger travel. The market is then projected to move into passenger travel. This would happen first in areas lacking road infrastructure and then in more congested areas. Early applications will likely include remote area access, military applications, and disaster recovery. These applications could require eVTOLs to refuel in off-grid locations and could therefore be particularly amenable to PV charging.

\subsection{Maritime}

The maritime sector is the next largest energy consuming transportation subsector after aviation. The most promising maritime fuel options include ammonia, methanol, and liquid hydrogen (Hydrogen Council 2021). PV can be an integral part of creating these fuels, and deep decarbonization of this sector would help drive more PV deployment.

The maritime market represents a timely opportunity for e-fuels created from PV. Operations of maritime vessels near shore (in Emissions Control Areas) effectively limit diesel fuels to those with a low sulfur content $(<0.1 \%)$. In international waters, the International Maritime Organization (IMO) has implemented rules that require a drop-in sulfur content from $3.5 \%$ to $0.5 \%$ starting in January 2020 (Hamilton 2018). Ships can no longer use the low-cost, highsulfur "bunker fuels" or "residual oil" that were once staples of the industry. According to EIA (U.S. Energy Information Administration 2019), maritime companies are complying with the new IMO sulfur rules in three basic ways:

1. Installation of emission exhaust scrubbers and continued use of bunker fuels. Scrubbers can be costly to install and can increase maintenance costs. Furthermore, they are a risky investment because the price and availability of higher-sulfur fuels after 2020 remains uncertain.

2. Use of lower-sulfur diesel. The upfront costs are low for this option, but this fuel is more expensive than bunker fuels. Low-sulfur fuel costs $20 \%-50 \%$ more than residual fuel because of additional hydroprocessing at refineries (Breakthrough 2020). EIA expects this difference to increase as demand for low-sulfur diesel increases.

3. Switching to alternative fuels. Most ships using this option have converted to liquefied natural gas. However, hydrogen or ammonia could be viable options as well. Electric batteries are likely not good candidates for powering ships, because their energy density is too low, so they would occupy too much space and weight. 


\subsubsection{Marine Vessels}

Across the maritime market, three common vessel types have recently been analyzed for alternative fuels: container ships, ferry ships, and tugboats (Ahluwalia, Papadias, and Wang 2020). Container ships and ferries have significant power and energy consumption, making them challenging for liquid-hydrogen applications (Ahluwalia, Papadias, and Wang 2020). These ships may be better suited for ammonia made from plentiful PV (DOE 2021). Tugboats have lower power and energy requirements, potentially making it easier for them to transition to green hydrogen or ammonia produced from PV. Recent analysis indicates that if DOE Hydrogen and Fuel Cell Technologies Office program targets are achieved, tugboats with fuel cell electric powertrains and liquid hydrogen onboard storage may provide a lower total cost of ownership than those that use low-sulfur diesel fuels (Ahluwalia, Papadias, and Wang 2020). These economics have an advantage over on-road hydrogen because marine applications have more concentrated refueling locations, maximizing the fuel throughput in each capital-intensive hydrogen station investment. This may provide a pathway toward coupling PV and large-scale hydrogen production and liquefaction.

\subsubsection{Shore Power}

Ships require a significant amount of power (from $500 \mathrm{~kW}$ to more than $10,000 \mathrm{~kW}$ ) when docking at a port, owing to loads such as air conditioning, lighting, and crew berths. This power is typically generated by diesel auxiliary engines. An alternative is to use shore power, which is grid electricity via a plug provided by the port. Shore power technology is relatively new in the commercial sector, but is well established in the U.S. Navy (US EPA 2017). Opportunities to create microgrids of installed PV, or simply connect to a larger grid with PV, should be evaluated and demonstrated in future work. 


\section{Conclusion}

The U.S. power sector is poised for continued and rapid evolution as an increasing number of cities, states, utilities, and businesses move toward aggressive decarbonization goals for 2035 and 2050. As part of this evolution, electrifying transportation through PEVs, FCEVs, and use of e-fuels will create new synergies between the transportation and power sectors. Specifically, shifting from fossil fuels to these new technologies will increase overall electricity demand, which can be met with renewable PV and wind resources. However, realizing this opportunity will require new technologies and approaches for increasing transportation load flexibility, which is critical to aligning transportation electricity demand with periods of PV generation and maintaining grid stability. In addition, technologies that reduce the cost of co-locating PV with vehicle charging and hydrogen production will be needed, as will enabling policies and market advancements.

For electric vehicles, technologies that enable wide-scale managed and coordinated charging are among the highest priorities for continued $\mathrm{R} \& \mathrm{D}$ in the near term, as their capabilities are foundational for future V2G functionality in the long term. In addition, vehicle batteries that can withstand a higher number of charge cycles are needed for V2G approaches that store excess PV generation and discharge it back to the grid. Higher-powered batteries could enable faster charging and improved alignment of charging loads with PV generation. In order to reduce deployment barriers to these technologies, a variety of new market and policy approaches will likely be needed, including time-varying rates and increased availability of workplace charging programs.

For hydrogen FCEVs, the use of PV electricity for electrolysis provides an opportunity to increase PV deployment. Specifically, flexible electrolyzers needed for hydrogen fuel production can help decrease peak grid load, reduce PV curtailment, and increase PV energy prices by providing an effective price floor for PV electricity sales. However, electrolyzers do not have access to wholesale electricity markets, which poses a barrier to fully maximizing PV deployment. With respect to vehicle technology advancements, FCEVs have the potential to support higher levels of $\mathrm{PV}$ penetration by acting as flexible power generators and providing electricity back to the grid. Other long-term priorities for increasing use of PV for hydrogen vehicles include the development of breakthrough technologies for liquefaction and hydrogen storage, as well as the buildout of hydrogen delivery and dispensing infrastructure. Market and policy approaches aimed at reducing deployment barriers include electrolyzer access to wholesale markets, power-to-gas implementation, and greater public awareness of the benefits provided by FCEVs.

For rail, air, and maritime transportation, the feasibility of increased PV use varies in the near term, though it improves in the long term. Near-term opportunities for synergies with solar include the electrification of rail, increased reliability from airport microgrids, and switching from diesel to synthetic maritime fuels. Over the longer term, battery swap stations for electric airplanes and the co-location of solar with hydrogen fueling stations at shipping ports may enable greater synergies between PV and transportation.

The opportunities and challenges for achieving greater synergies between PV and the transportation sector discussed in this report are not exhaustive. Rather, this research seeks to 
identify the near- and long-term priority advancements that are poised to have the greatest impact on increasing the use of PV for electric, hydrogen, rail, air, and maritime transportation. Areas for future research include the development and use of cross-sector modeling approaches to better understand interdependencies and impacts across electric and hydrogen transport. In addition, the full value proposition of widespread, low-cost PV electricity conversion into hydrogen as an energy carrier for other sectors is difficult to quantify due to the complex, integrated, and cross-sector modeling that needs to occur. Improved analysis tools that couple multiple sectors are needed to fully quantify the value proposition of hydrogen electrolysis to support high penetrations of solar energy in the electricity grid. Lastly, research and analysis to quantify the deployment potential associated with specific advancements and policies would be beneficial for further prioritization and ranking of possible R\&D pathways. 


\section{References}

Adler, Alan. 2020. "Toyota Equips Kenworth Class 8 Truck with Updated Fuel Cell." FreightWaves. December 10, 2020. https://www.freightwaves.com/news/toyota-equipskenworth-class-8-truck-with-updated-fuel-cell.

Ahluwalia, Rajesh K., Dimitris Papadias, and Xinchang Wang. 2020. "Rail and Maritime Metrics." Presented at the U.S. DOE Hydrogen and Fuel Cells Program 2020 Annual Merit Review and Peer Evaluation Meeting, Washington, D.C., May 19, 2020. https://www.hydrogen.energy.gov/pdfs/review20/ta034_ahluwalia_2020_o.pdf.

Ardani, Kristen, and Robert Margolis. 2015. Decreasing Soft Costs for Solar Photovoltaics by Improving the Interconnection Process: A Case Study of Pacific Gas and Electric. Golden, CO: National Renewable Energy Laboratory. NREL/TP 7A40-65066. https://www.nrel.gov/docs/fy15osti/65066.pdf.

Ardani, Kristen, Galen Barbose, Robert Margolis, Ryan Wiser, David Feldman, and Sean Ong. 2012. Benchmarking Non-Hardware Balance of System (Soft) Costs for U.S. Photovoltaic Systems Using a Data-Driven Analysis from PV Installer Survey Results. Golden, CO: National Renewable Energy Laboratory. NREL/TP-7A20-56806. https://www.nrel.gov/docs/fy13osti/56806.pdf.

Argonne National Laboratory (ANL). 2020. "Hydrogen Delivery Scenario Analysis Model (HDSAM).” Energy Systems. https://hdsam.es.anl.gov/index.php?content=hdsam.

Ashique, Ratil H. 2017. "Integrated Photovoltaic-Grid Dc Fast Charging System for Electric Vehicle: A Review of the Architecture and Control." Renewable and Sustainable Energy Reviews 69 (March): 1243-57.

Baldwin, Sara, Amanda Myers, and Michael O'Boyle. 2020. Increasing Electric Vehicle Charging Access at Multi-Unit Dwellings: Workshop Summary Report. San Francisco, CA: Energy Innovation Policy \& Technology, LLC. https://energyinnovation.org/wpcontent/uploads/2020/09/Increasing-Electric-Vehicle-Charging-at-Multi-UnitDwellings_FINAL3.pdf.

Barbose, Galen L., Sydney Forrester, Naïm R Darghouth, and Ben Hoen. 2020. Income Trends among U.S. Residential Rooftop Solar Adopters. Berkeley, CA: Lawrence Berkeley National Laboratory. 1603637. https://doi.org/10.2172/1603637.

Baronas, Jean, and Gerhard Achtelik. 2019. Joint Agency Staff Report on Assembly Bill 8: 2019 Annual Assessment of Time and Cost Needed to Attain 100 Hydrogen Refueling Stations in California. Sacramento, CA: California Energy Commission. CEC-600-2019-039. https://ww2.energy.ca.gov/2019publications/CEC-600-2019-039/CEC-600-2019-039.pdf.

Barrett, Stephen B. 2016. "ACRP Report 108: Guidebook for Energy Facilities Compatibility with Airports and Airspace." Presented in December 2016. https://hmmh.com/wpcontent/uploads/2016/12/Presentation SBB ACRP Report108 2015.pdf. 
Baskas, Harriet. 2019. "More Airports Consider Going off the Grid as Power Outages Ground Flights." CNBC. November 3, 2019. https://www.cnbc.com/2019/11/03/more-airports-considergoing-off-the-grid-to-avoid-power-outages.html.

Bloomberg. 2019. "Hydrogen: The Economics of Production from Renewables." https://www.bnef.com/insights/21213.

_. 2020. "A Million-Mile Battery from China Could Power Your Electric Car." June 7, 2020. https://www.bloomberg.com/news/articles/2020-06-07/a-million-mile-battery-from-chinacould-power-your-electric-car.

Borlaug, Brennan, Shawn Salisbury, Mindy Gerdes, and Matteo Muratori. 2020. "Levelized Cost of Charging Electric Vehicles in the United States.” Joule 4 (7): 1470-85.

https://doi.org/10.1016/j.joule.2020.05.013.

Bridgestone. 2020. “2021 Virtual Program.” World Solar Challenge.

https://www.worldsolarchallenge.org/.

Brooker, Aaron, Alicia Birky, Evan Reznicek, Jeff Gonder, Chad Hunter, Jason Lustbader, Jason Zhang, et al. Forthcoming. Vehicle Technologies and Hydrogen and Fuel Cells Technologies Research and Development Programs Benefits Assessment Report for 2020. Golden, CO: National Renewable Energy Laboratory. NREL/TP-5400-79617.

Bryson Taylor, Derrick. 2020. "Humans Take a Step Closer to 'Flying Cars." New York Times. August 29, 2020. https://www.nytimes.com/2020/08/29/world/asia/japan-flying-car.html.

Bulk Transporter. 2008. "Truckstop Diesel Volumes Decline.” Fleet Management: Tank Fleets. September 30, 2008. https://www.bulktransporter.com/fleet-management/tank-

fleets/article/21649166/truckstop-diesel-volumes-decline.

Burlig, Fiona, Jim Bushnell, Dave Rapson, and Catherine Wolfram. 2020. "Cars of the Future, Today?" Presented at the $35^{\text {th }}$ Annual Conference on Macroeconomics, National Bureau of Economic Research Energy Use in Transportation, July 2020.

Butler, Sydney. 2021. "8 Best Heavy Lift Drones for Sale 2021 [VERY Large Drones]." Drone Guru. January 8, 2021. https://www.droneguru.net/heavy-lift-drones-for-sale/.

California Air Resources Board (CARB). 2020. 2020 Annual Evaluation of Fuel Cell Electric Vehicle Deployment \& Hydrogen Fuel Station Network Development. Sacramento, CA. https://ww2.arb.ca.gov/sites/default/files/2020-09/ab8 report 2020.pdf.

California Public Utilities Commission (CPUC). 2020. Final Report of the California Joint Agencies Vehicle-Grid Integration Working Group. San Francisco, CA. R.18-12-006. https://gridworks.org/wp-content/uploads/2020/07/VGI-Working-Group-Final-Report6.30.20.pdf. 
Cappers, Peter, Liesel Hans, and Richard Scheer. 2015. American Recovery and Reinvestment Act of 2009: Interim Report on Customer Acceptance, Retention, and Response to Time-Based Rates from the Consumer Behavior Studies. Berkeley, CA: Lawrence Berkeley National Laboratory. LBNL-183029. https:/eta-publications.lbl.gov/sites/default/files/lbnl-183029.pdf.

Concawe. 2017. "Marine Fuel Facts.” https://www.concawe.eu/publication/marine-fuel-facts/.

Connelly, Elizabeth, Michael Penev, Amgad Elgowainy, and Chad Hunter. 2019. "Current Status of Hydrogen Liquefaction Costs." DOE Hydrogen and Fuel Cells Program Record 19001. Washington, D.C.: U.S. Department of Energy. https://www.hydrogen.energy.gov/pdfs/19001_hydrogen_liquefaction_costs.pdf.

Cook, Jeffrey J., Kristen B. Ardani, Eric J. O’Shaughnessy, Robert M. Margolis, and Brittany Smith. 2018. Expanding PV Value: Lessons Learned from Utility-Led Distributed Energy Resource Aggregation in the United States. Golden, CO: National Renewable Energy Laboratory. NREL/TP-6A20-71984, 1483067. https://doi.org/10.2172/1483067.

Debnath, Uttam Kumar, Iftekhar Ahmad, and Daryoush Habibi. 2014. "Quantifying Economic Benefits of Second Life Batteries of Gridable Vehicles in the Smart Grid." International Journal of Electrical Power \& Energy Systems 63 (December): 577-87. https://doi.org/10.1016/j.ijepes.2014.05.077.

DOE (U.S. Department of Energy). 2021. Solar Futures Study. DOE/GO-102021-5621. Washington, D.C.: U.S. Department of Energy Office of Energy Efficiency and Renewable Energy. https://www.energy.gov/eere/solar/solar-futures-study.

Duve, Mark. 2019. "Norfolk Southern: Locomotive Hydrogen Fuel Perspective.” Presented at the U.S. Department of Energy H2@Rail Workshop, March 27, 2019. https://www.energy.gov/sites/prod/files/2019/04/f62/fcto-h2-at-rail-workshop-2019-duve.pdf.

Edison Electric Institute (EEI). 2019. “Electric Vehicle Sales: Facts \& Figures.” Presented in April 2019.

https://www.eei.org/issuesandpolicy/electrictransportation/Documents/FINAL_EV_Sales_Updat e_April2019.pdf.

Edwards, Reace Louise, Carolina Font-Palma, and Joe Howe. 2021. "The Status of Hydrogen Technologies in the UK: A Multi-Disciplinary Review." Sustainable Energy Technologies and Assessments 43 (February): 100901. https://doi.org/10.1016/j.seta.2020.100901.

Eichman, Josh, Mariya Koleva, Omar J. Guerra, and Brady McLaughlin. 2020. Optimizing an Integrated Renewable-Electrolysis System. Golden, Colorado: National Renewable Energy Laboratory. NREL/TP-5400-75635. https://www.nrel.gov/docs/fy20osti/75635.pdf.

Elgowainy, Amgad, Marianne Mintz, Uising Lee, Thomas Stephens, Pingping Sun, Yan Zhou, and Guiyan Zang. 2020. Assessment of the Potential Demand for Hydrogen in Vehicle and Industrial Applications. Argonne, IL: Argonne National Laboratory. ANL-20/35. https://greet.es.anl.gov/files/us_future_h2. 
Engle, Hauke, Patrick Hertzke, and Giulia Siccardo. 2019. Second-Life EV Batteries: The Newest Value Pool in Energy Storage. McKinsey \& Company.

https://www.mckinsey.com/ /media/McKinsey/Industries/Automotive $\% 20$ and $\% 20 \mathrm{Assembly} / \mathrm{Ou}$ r\%20Insights/Second\%20life\%20EV\%20batteries\%20The\%20newest $\% 20$ value $\% 20$ pool\%20in

$\% 20$ energy\%20storage/Second-life-EV-batteries-The-newest-value-pool-in-energy-storage.ashx.

Eshraghi, Nicolas, Loris Berardo, Audrey Schrijnemakers, Vincent Delaval, Mahdokht Shaibani, Mainak Majumder, Rudi Cloots, et al. 2020. "Recovery of Nano-Structured Silicon from End-ofLife Photovoltaic Wafers with Value-Added Applications in Lithium-Ion Battery." ACS Sustainable Chemistry \& Engineering 8 (15): 5868-79.

https://doi.org/10.1021/acssuschemeng.9b07434.

Eudy, Leslie, and Matthew Jeffers. 2017. Foothill Transit Battery Electric Bus Demonstration Results: Second Report. Golden, CO: National Renewable Energy Laboratory. NREL/TP-540067698. https://www.nrel.gov/docs/fy17osti/67698.pdf.

Eudy, Leslie, and Matthew Jeffers. 2018. Zero-Emission Bus Evaluation Results: County Connection Battery Electric Buses. Golden, CO: National Renewable Energy Laboratory. NREL/TP-5400-72864. https://www.nrel.gov/docs/fy19osti/72864.pdf

Eudy, Leslie. 2019. "Technology Acceleration: Fuel Cell Bus Evaluations." Presented at the DOE Hydrogen and Fuel Cells Program 2019 Annual Merit Review and Peer Evaluation Meeting, Crystal City, Virginia, May 1, 2019. https://www.nrel.gov/docs/fy19osti/73407.pdf.

Euro NCAP. 2018. "Hyundai NEXO Standard Safety Equipment - Test Results." https://www.euroncap.com/en/results/hyundai/nexo/33731.

Geisz, John F., Ryan M. France, Kevin L. Schulte, Myles A. Steiner, Andrew G. Norman, Harvey L. Guthrey, Matthew R. Young, Tao Song, and Thomas Moriarty. 2020. "Six-Junction III-V Solar Cells with 47.1\% Conversion Efficiency under 143 Suns Concentration." Nature Energy 5 (4): 326-35. https://doi.org/10.1038/s41560-020-0598-5.

Hamilton, Mason. 2018. "Coming Changes in Marine Fuel Sulfur Limits Will Affect Global Oil Markets.” Today in Energy. December 14, 2018. U.S. Energy Information Administration. https://www.eia.gov/todayinenergy/detail.php?id=37793.

Hledik, Ryan, Ahmad Faruqui, and Cody Warner. 2017. "The National Landscape of Residential TOU Rates.” Presented in November 2017. https://tinyurl.com/ybw2cco4.

Ho, Clifford K. 2013. "Solar Glare and Flux Analysis Tools." Solar Glare Tools. Sandia National Laboratories. https://share-ng.sandia.gov/glare-tools/.

Hoffrichter, Andreas. 2019. "Hydrogen-Rail (Hydrail) Development." Presented at the U.S. Department of Energy H2@Rail Workshop. March 27, 2019.

https://www.energy.gov/sites/prod/files/2019/04/f62/fcto-h2-at-rail-workshop-2019hoffrichter.pdf. 
Homann, Quailan. 2020. "A Case for Hydrogen to Decarbonize Mining." Fuel Cell \& Hydrogen Energy Association. March 16, 2020. https://www.fchea.org/in-transition/2020/3/16/a-case-forhydrogen-to-decarbonize-mining.

Hunter, Chad, Brian Bush, Elizabeth Connelly, and Michael Penev. Forthcoming. Hydrogen Supply Chain Dynamics Using the Scenario Evaluation and Regionalization Analysis (SERA) Model: An Application to Light-Duty Vehicles. Golden, Colorado: National Renewable Energy Laboratory. NREL/TP-5400-71480.

Hunter, Chad, Michael Penev, Evan P. Reznicek, Joshua Eichman, Neha Rustagi, and Samuel F. Baldwin. 2021. "Techno-Economic Analysis of Long-Duration Energy Storage and Flexible Power Generation Technologies to Support High Variable Renewable Energy Grids." Joule. https://doi.org/10.2139/ssrn.3720769.

Hunter, Chad, Michael Penev, Evan Reznicek, Jason Lustbader, Alicia Birky, and Chen Zhang. 2021. Market Segmentation Analysis of Medium- and Heavy-Duty Trucks: A Total Cost of Ownership Approach. Golden, Colorado: National Renewable Energy Laboratory. NREL/TP5400-71796.

Hydrogen Council. 2017a. How Hydrogen Empowers the Energy Transition. January 15, 2017. Brussels, Belgium. https://hydrogencouncil.com/en/study-how-hydrogen-empowers/.

Hydrogen Council. 2017b. Hydrogen, Scaling Up. November 13, 2017. Brussels, Belgium. https://hydrogencouncil.com/en/study-hydrogen-scaling-up/.

Hydrogen Council. 2021. Hydrogen Insights 2021. July 15, 2021. Brussels, Belgium. https:/hydrogencouncil.com/en/hydrogen-insights-2021/.

International Energy Agency (IEA). 2020a. Global EV Outlook 2020. Paris, France. https://www.iea.org/reports/global-ev-outlook-2020.

International Energy Agency (IEA). 2020b. Global EV Outlook 2020 - Analysis. Paris, France. https://www.iea.org/analysis

Iribarren, Diego, Mario Martín-Gamboa, Javier Manzano, and Javier Dufour. 2016. “Assessing the Social Acceptance of Hydrogen for Transportation in Spain: An Unintentional Focus on Target Population for a Potential Hydrogen Economy." International Journal of Hydrogen Energy 41 (10): 5203-8. https://doi.org/10.1016/j.ijhydene.2016.01.139.

Jeffers, Matthew A., Larry Chaney, and John P. Rugh. 2015. Climate Control Load Reduction Strategies for Electric Drive Vehicles in Warm Weather. SAE Technical Paper 2015-01-0355. April 14, 2015. https://doi.org/10.4271/2015-01-0355.

Joseck, Fred, and Erika Sutherland. 2015. "Early Market Hydrogen Cost Target Calculation2015 Update.” DOE Fuel Cell Technologies Office Record 15012. Washington, D.C. https://www.hydrogen.energy.gov/pdfs/15012 hydrogen_early market_cost target_2015 updat e.pdf. 
Jun, Myungsoo, and Andrew Meintz. 2018. "Workplace Charge Management with Aggregated Building Loads." Presented at the 2018 IEEE Transportation Electrification Conference and Expo (ITEC), Long Beach, California, June 13-15, 2018. https://doi.org/10.1109/ITEC.2018.8450227.

Kiani, Behdad. 2020. "ZEV Vehicle Adoption and Variable Renewable Electric Power." Webinar. July 22. https://www.youtube.com/watch?v=Lusp14TqiWQ\&feature=youtu.be.

Larson, Eric, Chris Greig, Jesse Jenkins, Erin Mayfield, Andrew Pascale, Chuan Zhang, Joshua Drossman, et al. 2020. Net-Zero America: Potential Pathways, Infrastructure, and Impacts. Princeton, NJ: Princeton University. https://netzeroamerica.princeton.edu/the-report.

Levin, Alan. 2019. "Google Spinoff’s Drone Delivery Business First to Get FAA Approval." Bloomberg: Hyperdrive. April 23, 2019. https://www.bloomberg.com/news/articles/2019-0423/alphabet-s-drone-delivery-business-cleared-for-takeoff-by-faa.

Lohse-Busch, Henning. 2012. Advanced Technology Vehicle Lab Benchmarking: Level 1. 2013. U.S. DOE Hydrogen and Fuel Cell Program and Vehicle Technologies Program Annual Merit Review and Peer Evaluation Meeting. May 14, 2013. https://www.energy.gov/sites/prod/files/2014/03/f13/vss030_lohsebusch_2013 o.pdf

Mai, Trieu, Paige Jadun, Jeffrey Logan, Colin McMillan, Matteo Muratori, Daniel Steinberg, Laura Vimmerstedt, Ryan Jones, Benjamin Haley, and Brent Nelson. 2018. Electrification Futures Study: Scenarios of Electric Technology Adoption and Power Consumption for the United States. Golden, CO: National Renewable Energy Laboratory. NREL/TP-6A20-71500. https://www.nrel.gov/docs/fy18osti/71500.pdf.

Malay-Mail. 2019. "Google Completes First Drone Delivery in the US." Home/Tech/Gadgets. October 20, 2019. https:/www.malaymail.com/news/tech-gadgets/2019/10/20/googlecompletes-first-drone-delivery-in-the-us/1801941.

Marcinkoski, Jason. 2019. "Hydrogen Class 8 Long Haul Truck Targets.” Program Record 19006. Washington, D.C.: U.S. Department of Energy. https://www.hydrogen.energy.gov/pdfs/19006_hydrogen_class8_long_haul_truck targets.pdf.

Mathews, Ian, Bolun Xu, Wei He, Vanessa Barreto, Tonio Buonassisi, and Ian Marius Peters. 2020. "Technoeconomic Model of Second-Life Batteries for Utility-Scale Solar Considering Calendar and Cycle Aging." Applied Energy 269 (July): 115127. https://doi.org/10.1016/j.apenergy.2020.115127.

Melaina, Marc, O. Antonia, and M. Penev. 2013. Blending Hydrogen into Natural Gas Pipeline Networks: A Review of Key Issues. Golden, CO: National Renewable Energy Laboratory. NREL/TP-5600-51995. https://www.nrel.gov/docs/fy13osti/51995.pdf.

Morgan Stanley. 2019. “Are Flying Cars Preparing for Takeoff?” Research. January 23, 2019. https://www.morganstanley.com/ideas/autonomous-aircraft. 
Muehlegger, Erich, and David S. Rapson. 2018. "Subsidizing Low- and Middle-Income Adoption of Electric Vehicles: Quasi-Experimental Evidence from California." Cambridge, MA: National Bureau of Economic Research. Working paper 25359. https://doi.org/10.3386/w25359.

Muenster, Matt. 2020. "How 2020 Sulfur Regulations Will Impact Diesel Prices." Breakthrough. April 10, 2020. https://www.breakthroughfuel.com/blog/sulfur-2020-diesel-prices/.

Muratori, Matteo, Eleftheria Kontou, and Joshua Eichman. 2019. "Electricity Rates for Electric Vehicle Direct Current Fast Charging in the United States." Renewable and Sustainable Energy Reviews 113 (October): 109235. https://doi.org/10.1016/j.rser.2019.06.042.

Myers, Erica. 2020. A Comprehensive Guide to Electric Vehicle Managed Charging. Washington, D.C.: Smart Electric Power Alliance. https://sepapower.org/resource/acomprehensive-guide-to-electric-vehicle-managed-charging/.

National Academies of Sciences, Engineering, and Medicine. 2011. Investigating Safety Impacts of Energy Technologies on Airports and Aviation. Washington, D.C.: The National Academies Press. http://www.trb.org/Publications/Blurbs/166099.aspx.

National Renewable Energy Laboratory (NREL). 2017. "Electric Ground Support Equipment at Airports." Golden, Colorado: National Renewable Energy Laboratory. NREL/FS-5400-70359. https://afdc.energy.gov/files/u/publication/egse_airports.pdf.

- 2019. "H2A: Hydrogen Analysis Production Case Studies - Hydrogen Production from PEM Electrolysis." Hydrogen \& Fuel Cells. September 2019. https://www.nrel.gov/hydrogen/h2a-production-models.html

Technology Baseline: Electricity. https://atb.nrel.gov/

Nelder, Chris, and Emily Rogers. 2019. Reducing EV Charging Infrastructure Costs. Boulder, CO: Rocky Mountain Institute. https://rmi.org/ev-charging-costs.

Nikola Motor. 2019. "Nikola Two.” 2019. https://nikolamotor.com/two.

- 2020. "Nikola Orders Enough Electrolysis Equipment From Nel to Produce 40,000 Kgs of Hydrogen Per Day." June 3, 2020. https://nikolamotor.com/press releases/nikola-ordersenough-electrolysis-equipment-from-nel-to-produce-40000-kgs-of-hydrogen-per-day-79.

Nunno, Richard. 2018. "Electrification of U.S. Railways: Pie in the Sky, or Realistic Goal?" Environmental and Energy Study Institute. May 30, 2018.

www.eesi.org/articles/view/electrification-of-u.s.-railways-pie-in-the-sky-or-realistic-goal.

O'Shaughnessy, Eric, and Kristen Ardani. 2020. "Distributed Rate Design: A Review of Early Approaches and Practical Considerations for Value of Solar Tariffs." The Electricity Journal 33 (3): 106713. https://doi.org/10.1016/j.tej.2020.106713. 
O’Shaughnessy, Eric, Galen Barbose, and Ryan Wiser. 2020. "Patience Is a Virtue: A Datadriven Analysis of Rooftop Solar PV Permitting Timelines in the United States." Energy Policy 144. https://doi.org/10.1016/j.enpol.2020.111615

Oberhaus, Daniel. 2020. "Charge a Car Battery in 5 Minutes? That's the Plan.” Wired. March 30, 2020. https://www.wired.com/story/charge-a-car-battery-in-5-minutes-that's-the-plan/.

Ong, Sean, Clinton Campbell, Paul Denholm, Robert Margolis, and Garvin Heath. 2013. LandUse Requirements for Solar Power Plants in the United States. Golden, Colorado: National Renewable Energy Laboratory. NREL/TP-6A20-56290. https://www.nrel.gov/docs/fy13osti/56290.pdf.

Penev, Michael, Jarett Zuboy, and Chad Hunter. 2019. "Economic Analysis of a High-Pressure Urban Pipeline Concept (HyLine) for Delivering Hydrogen to Retail Fueling Stations." Transportation Research Part D: Transport and Environment 77 (December): 92-105. https://doi.org/10.1016/j.trd.2019.10.005.

Pyper, Julia. 2018. "BMW's Plan to Optimize EV Charging With Renewables on the Grid." Greentech Media. August 27, 2018. https://www.greentechmedia.com/articles/read/bmwoptimizing-ev-charging-renewable-energy.

Qian, Fanyue, Weijun Gao, Yongwen Yang, and Dan Yu. 2020. "Economic Optimization and Potential Analysis of Fuel Cell Vehicle-to-Grid (FCV2G) System with Large-Scale Buildings." Energy Conversion and Management 205 (February). https://doi.org/10.1016/j.enconman.2019.112463.

Reese, Matthew O., Stephen Glynn, Michael D. Kempe, Deborah L. McGott, Matthew S. Dabney, Teresa M. Barnes, Samuel Booth, David Feldman, and Nancy M. Haegel. 2018. "Increasing Markets and Decreasing Package Weight for High-Specific-Power Photovoltaics." Nature Energy 3 (11): 1002-12. https://doi.org/10.1038/s41560-018-0258-1.

Ricci, Miriam, Paul Bellaby, and Rob Flynn. 2008. "What Do We Know About Public Perceptions and Acceptance of Hydrogen? A Critical Review and New Case Study Evidence." International Journal of Hydrogen Energy 33 (21): 5868-80.

https://doi.org/10.1016/j.ijhydene.2008.07.106.

Richardson, David B. 2013. "Electric Vehicles and the Electric Grid: A Review of Modeling Approaches, Impacts, and Renewable Energy Integration." Renewable and Sustainable Energy Reviews 19 (March): 247-54. https://doi.org/10.1016/j.rser.2012.11.042.

Robledo, Carla B., Vincent Oldenbroek, Francesca Abbruzzese, and Ad J. M. van Wijk. 2018. "Integrating a Hydrogen Fuel Cell Electric Vehicle with Vehicle-to-Grid Technology, Photovoltaic Power and a Residential Building." Applied Energy 215 (April): 615-29. https://doi.org/10.1016/j.apenergy.2018.02.038.

Roeth, Mike. 2020. “Keeping Trucking Cool.” Rocky Mountain Institute. August 6, 2020. https://rmi.org/keeping-trucking-cool/. 
Ruth, Mark, Paige Jadun, Nicholas Gilroy, Elizabeth Connelly, Richard Boardman, A. J. Simon, Amgad Elgowainy, and Jarett Zuboy. 2020. "The Technical and Economic Potential of the H2@Scale Hydrogen Concept within the United States." Golden, CO: National Renewable Energy Laboratory. NREL/TP-6A20-77610, 1677471, MainId:29536.

https://doi.org/10.2172/1677471.

Satyapal, Sunita. 2020. "DOE Hydrogen and Fuel Cell Perspectives and Overview of the International Partnership for Hydrogen and Fuel Cells in the Economy (IPHE)." July 29,2020. https://www.energy.gov/eere/fuelcells/downloads/doe-hydrogen-and-fuel-cell-perspectives-andoverview-iphe-global-america

- 2021. "DOE Hydrogen Program Overview." Presented at the DOE Annual Merit Review, June 7, 2021. https://www.hydrogen.energy.gov/pdfs/review21/plenary5_satyapal_2021_o.pdf.

Saur, Genevieve, Spencer Gilleon, and Sam Sprik. 2021. "Next Generation Hydrogen Station Composite Data Products: Retail Stations; Summer 2020: Data through Quarter 2 of 2020." Presented in February 2021. NREL/PR-5400-79141, 1782589 , MainId:33367. https://doi.org/10.2172/1782589.

Schäfer, Andreas W., Steven R. H. Barrett, Khan Doyme, Lynnette M. Dray, Albert R. Gnadt, Rod Self, Aidan O’Sullivan, Athanasios P. Synodinos, and Antonio J. Torija. 2019. "Technological, Economic and Environmental Prospects of All-Electric Aircraft." Nature Energy 4 (2): 160-66. https://doi.org/10.1038/s41560-018-0294-X.

Slowik, Peter, and Nic Lutsey. 2018. "The Continued Transition to Electric Vehicles in U.S. Cities." Washington, D.C.: International Council on Clean Transportation. White paper. https://theicct.org/publications/continued-EV-transition-us-cities-2018.

Smart Electric Power Alliance (SEPA). 2020. Utility Best Practices for EV Infrastructure Deployment. Washington, D.C. https://sepapower.org/resource/best-practices-for-utility-evinfrastructure-deployment/.

Stang, John. 2018. "This Boeing-Backed Company Is Planning to Make Electric Airplanes." Seattle Business Magazine. July 17, 2018. https://www.seattlebusinessmag.com/businessoperations/boeing-backed-company-planning-make-electric-airplanes.

Sun, Yinong, Paige Jadun, Brent Nelson, Matteo Muratori, Caitlin Murphy, Jeffrey Logan, and Trieu Mai. 2020. Electrification Futures Study: Methodological Approaches for Assessing LongTerm Power System Impacts of End-Use Electrification. Golden, CO: National Renewable Energy Laboratory. NREL/TP-6A20-73336. https://doi.org/10.2172/1660122.

Sunter, Deborah A., Sergio Castellanos, and Daniel M. Kammen. 2019. "Disparities in Rooftop Photovoltaics Deployment in the United States by Race and Ethnicity." Nature Sustainability 2 (1): 71-76. https://doi.org/10.1038/s41893-018-0204-z. 
Tomaszewska, Anna, Zhengyu Chu, Xuning Feng, Simon O'Kane, Xinhua Liu, Jingyi Chen, Chenzhen Ji, et al. 2019. Lithium-Ion Battery Fast Charging: A Review. eTransportation (1) 100011 https://doi.org/10.1016/j.etran.2019.100011.

Toyota. 2019. "NEDO, Sharp, and Toyota to Begin Public Road Trials of Electrified Vehicles Equipped with High-Efficiency Solar Batteries.” Toyota. July 4, 2019. https://global.toyota/en/newsroom/corporate/28787347.html.

U.S. Census Bureau. 2019. “U.S. Census Bureau QuickFacts: California.” July 2019. https://www.census.gov/quickfacts/CA.

U.S. Department of Energy (DOE). 2017. "Pump Up the Charge with Extreme Fast Charging." January 6, 2017. https://www.energy.gov/eere/articles/pump-charge-extreme-fast-charging.

—. 2021a. "Alternative Fueling Station Locator." Alternative Fuels Data Center. https://afdc.energy.gov/stations/\#/find/nearest.

—. 2021b. "Alternative Fuels Data Center: Federal and State Laws and Incentives." Alternative Fuels Data Center. https://afdc.energy.gov/laws.

U.S. Department of Transportation. 2017. Summary of Travel Trends: National Household Travel Survey. Washington, D.C. https://nhts.ornl.gov/assets/2017_nhts summary travel trends.pdf.

—. 2019. "National Transportation Statistics (Series)." https://doi.org/10.21949/1503663.

U.S. Energy Information Administration (EIA). 2019. The Effects of Changes to Marine Fuel Sulfur Limits in 2020 on Energy Markets. Washington, D.C. https://www.eia.gov/outlooks/studies/imo/pdf/IMO.pdf.

_.2020. "Electricity Explained-Electricity in the United States." https://www.eia.gov/energyexplained/electricity/electricity-in-the-us.php.

—. 2021. Annual Energy Outlook 2021. Washington, D.C.

https://www.eia.gov/outlooks/aeo/.

U.S. Environmental Protection Agency (EPA). 2017. Shore Power Technology Assessment at U.S. Ports." Washington, D.C.: Office of Transportation and Air Quality. https://www.epa.gov/ports-initiative/shore-power-technology-assessment-us-ports.

- 2018. "Fast Facts on Transportation Greenhouse Gas Emissions." Overviews and Factsheets. https://www.epa.gov/greenvehicles/fast-facts-transportation-greenhouse-gasemissions.

University of California Los Angeles (UCLA). 2017. Factors Affecting Plug-in Electric Vehicle Sales in California. Sacramento, CA: California Air Resources Board. https://ww2.arb.ca.gov/sites/default/files/classic//research/apr/past/13-303.pdf. 
Vanderwerp, Dave. 2019. "Porsche Taycan's 800-Volt Architecture Enables Slimmer Wiring, Faster Charging, Less Heat." Car and Driver. September 6, 2019.

https://www.caranddriver.com/news/a28903284/porsche-taycan-ev-800-volt-chargingperformance/.

Vekony, Atilla. 2010. "Recycling: A Solar Panel's Life after Death." GreenMatch. March 24, 2021. https://www.greenmatch.co.uk/blog/2017/10/the-opportunities-of-solar-panel-recycling.

Verger, Rob. 2019. "Does Hyundai's Rooftop Solar Panel Change the Fuel-Economy Equation?" Popular Science. August 23, 2019. https://www.popsci.com/hyundai-hybrid-car-solar-panel/.

Wang, Dai, Jonathan Coignard, Teng Zeng, Cong Zhang, and Samveg Saxena. 2016.

"Quantifying Electric Vehicle Battery Degradation from Driving vs. Vehicle-to-Grid Services." Journal of Power Sources 332 (November): 193-203.

https://doi.org/10.1016/i.jpowsour.2016.09.116.

Wang, Dai, Matteo Muratori, Joshua Eichman, Max Wei, Samveg Saxena, and Cong Zhang. 2018. "Quantifying the Flexibility of Hydrogen Production Systems to Support Large-Scale Renewable Energy Integration.” Journal of Power Sources 399 (September): 383-91. https://doi.org/10.1016/j.jpowsour.2018.07.101.

Whited, Melissa, Avi Allison, and Rachel Wilson. 2018. Driving Transportation Electrification Forward in New York. Cambridge, MA: Synapse Energy Economics. http://www.synapseenergy.com/sites/default/files/NY-EV-Rate-\%20Report-18-021.pdf.

Zhang, Cong, Jeffery B. Greenblatt, Max Wei, Josh Eichman, Samveg Saxena, Matteo Muratori, and Omar J. Guerra. 2020. "Flexible Grid-Based Electrolysis Hydrogen Production for Fuel Cell Vehicles Reduces Costs and Greenhouse Gas Emissions." Applied Energy 278 (November): 115651. https://doi.org/10.1016/j.apenergy.2020.115651v. 


\section{Appendix. Estimating Total Electricity Requirement for Deep Decarbonization of the Transportation Sector}

The Electrification Futures Study (EFS) (Mai et al. 2018) provides a detailed assessment of electrification of the transportation sector. The "High" electrification scenario from the EFS (which corresponds to Decarb+E here) results in about $75 \%$ of all vehicle miles traveled (VMT) from electric vehicles by 2050 . Despite this significant level of electrification, about $70 \%$ of total 2050 transportation sector energy use is estimated to still rely on fossil-based fuels, reflecting the greater fuel economy of electric vehicles. The EFS did not analyze electrification potential beyond on-road transportation or indirect electrification.

A simplified analysis can help elucidate the potential impacts of deep decarbonization of the transportation sector on solar energy production requirements. First, energy efficiency improvements for each transportation subsector beyond those assumed in the 2020 AEO Outlook Reference scenarios must be accounted for. Second, the relative market shares of low- or zerocarbon based fuels must be assessed for each transportation subsector. Finally, a relative fuel economy adjustment must be made to account for the powertrain efficiency difference between the conventional fuel and the low- or zero-carbon fuel within each transportation subsector. Several literature sources, industry projections, and NREL transportation sector modeling were leveraged to complete each of these three steps.

First, energy efficiency improvements for each transportation subsector need to be estimated. Due to limited data, we estimated energy efficiency improvements for on-road vehicles and aviation, while all other subsectors were assumed to match the 2020 AEO Reference scenario.

For on-road vehicles: A recent NREL analysis of advanced powertrain adoption across the onroad vehicle sector was used (Brooker et al. 2021). Specifically, for light-duty passenger vehicles, NREL ADOPT model estimates of internal combustion engine vehicle efficiency approximately match the 2020 AEO Outlook Reference scenario, so no further reductions in subsector energy use were estimated. For medium duty trucks, the 2020 AEO Reference scenario projections imply a Class 4-6 fuel economy of $\sim 12.9$ miles per diesel gallon equivalent (MPDGE), while the NREL analysis estimates a fuel economy of 21.4 MPDGE due to improved engine efficiency, lightweighting, and aerodynamics from achieving U.S. DOE Vehicle Technology Office and Supertruck targets. Thus, the final energy use from the 2020 AEO Outlook was reduced by $\sim 40 \%$ to account for this improvement in MDV energy efficiency. A similar process was followed for heavy-duty trucks and buses. However, for heavy-duty trucks, three segments were evaluated in the NREL analysis; these were weighted by their relative 2050 fuel consumption to obtain a weighted-average fuel economy for that subsector. While buses were not evaluated in the NREL analysis, a Class 7-8 Vocational truck was used as a surrogate due to its similar drive-cycle. The resulting energy efficiency improvements were estimated to be $\sim 33 \%$ for heavy duty trucks and $\sim 32 \%$ for buses.

For aviation: A flat energy efficiency improvement of $1.5 \%$ per year beyond the AEO Outlook was assumed, based on recent net-zero economy modeling (Larson et al. 2020). This improvement was assumed to offset growing passenger travel demands. 
Next, market shares for the low- or zero-carbon fuel types must be estimated along with any potential differences in powertrain fuel efficiency. Table 5 summarizes those assumptions and data.

On-road transportation segment: The LDV market share is approximated based on (Brooker et al. 2021), which shows that BEVs are likely the most promising zero emission vehicle powertrain technology. MDV/HDV and bus market shares are approximated based on the estimated 2050 market shares in (Brooker et al. 2021). While that analysis did not achieve a netzero transportation system, it indicates that there will be a complementary set of powertrain designs to achieve full decarbonization. For MDVs, battery electric and fuel cell electric powertrains are adopted in near equal proportions. Given the lower energy and range requirements of these vehicles, it was assumed this market share split would continue until full decarbonization, without a need for liquid fuels. For HDVs, Brooker et al. evaluated three vocations: Class 7 and 8 vocational trucks, day cabs, and sleepers. Based on the relative 2050 market share splits that Brooker et al. estimated, it is assumed that $\sim 25 \%$ of a net-zero HDV market will be fully battery electric, $\sim 50 \%$ will be based on hydrogen fuel cells, and $\sim 25 \%$ will utilize biofuels. While biofuels were not explicitly modeled in (Brooker et al. 2021), they will likely be needed due to stock turnover limitations, and they may be suitable for certain energyintense duty cycles. The fuel economy ratio of HDVs was based on an energy-weighted average across the three Class 7 and 8 segments modeled. Buses were assumed to have the same market share breakdown as HDVs, but with a fuel economy ratio based on the Class 7 and 8 vocational trucks.

Non-road transportation segments: The hydrogen market share for rail is based on (Hydrogen Council 2017), while an assumed 50/50 split of drop-in biofuels and synfuels are assumed for the remaining market. Maritime is segmented by total cost of ownership, route length, stop frequency, and whether the ship types carry passengers. Ammonia was assumed for ships with long routes, less frequent stops, no passengers, and lower potential total cost of ownership in that segment (offshore, liquid gas tanker, chemical tanker, cargo, oil tanker, bulk carrier, and container). Methanol was assumed for ships with shorter routes, more frequent stops, potential for passengers, and lower potential total cost of ownership in that segment (vehicle, cruise, fishing, RoRo/RoPax) (Hydrogen Council 2021; Concawe 2017). Electrification of aviation was assumed to occur for flights less than $\sim 1,000 \mathrm{~km}$ (commuter, regional aircraft) (Schäfer et al. 2019). Similarly, hydrogen turbines were assumed for short-range aircraft $(\sim 2,000 \mathrm{~km})$, and synfuels were assumed for medium- and long-range aircrafts (Hydrogen Council 2021). For the military subsector, a 50/50 split of drop-in biofuels and synfuels was assumed. For lubricants, $100 \%$ drop-in synfuels was assumed.

Table 5. Summary of Estimated Low- and Zero-Carbon Fuel Market Shares, Fuel Economy Ratios, and References

\begin{tabular}{|c|c|c|c|c|c|}
\hline $\begin{array}{c}\text { AEO } \\
\text { Subsector }\end{array}$ & $\begin{array}{c}\text { Low-Carbon } \\
\text { Fuel }\end{array}$ & $\begin{array}{c}\text { Subsector } \\
\text { Market } \\
\text { Share }\end{array}$ & $\begin{array}{c}\text { Fuel } \\
\text { Economy } \\
\text { Ratio }\end{array}$ & $\begin{array}{l}\text { Market Share } \\
\text { Reference }\end{array}$ & $\begin{array}{c}\text { Fuel Economy } \\
\text { Reference }\end{array}$ \\
\hline LDV & Electric & 1 & 2.6 & \multirow{3}{*}{$\begin{array}{l}\text { Approximated based } \\
\text { on } \\
\text { (Brooker et al. 2021) }\end{array}$} & (Brooker et al. 2021) \\
\hline MDV & Electric & 0.5 & 2.8 & & (Brooker et al. 2021) \\
\hline MDV & Hydrogen & 0.5 & 1.9 & & (Brooker et al. 2021) \\
\hline
\end{tabular}




\begin{tabular}{|c|c|c|c|c|c|}
\hline $\begin{array}{c}\text { AEO } \\
\text { Subsector }\end{array}$ & $\begin{array}{c}\text { Low-Carbon } \\
\text { Fuel }\end{array}$ & $\begin{array}{l}\text { Subsector } \\
\text { Market } \\
\text { Share }\end{array}$ & $\begin{array}{l}\text { Fuel } \\
\text { Economy } \\
\text { Ratio }\end{array}$ & $\begin{array}{l}\text { Market Share } \\
\text { Reference }\end{array}$ & $\begin{array}{l}\text { Fuel Economy } \\
\text { Reference }\end{array}$ \\
\hline Buses & Electric & 0.25 & 2.7 & & (Brooker et al. 2021) \\
\hline Buses & Hydrogen & 0.50 & 1.8 & & (Brooker et al. 2021) \\
\hline Buses & Biofuels & 0.25 & 1 & & Drop-in fuel \\
\hline HDV & Electric & 0.25 & 2.2 & & (Brooker et al. 2021) \\
\hline HDV & Hydrogen & 0.50 & 1.4 & & (Brooker et al. 2021) \\
\hline HDV & Biofuels & 0.25 & 1 & & Drop-in fuel \\
\hline Rail & Biofuels & 0.4 & 1 & $\begin{array}{l}50 \% \text { of remaining } \\
\text { market-share }\end{array}$ & Drop-in fuel \\
\hline Rail & Synfuels & 0.4 & 1 & $\begin{array}{l}50 \% \text { of remaining } \\
\text { market-share }\end{array}$ & Drop-in fuel \\
\hline Rail & Hydrogen & 0.2 & 1.15 & $\begin{array}{l}\text { (Hydrogen Council } \\
\text { 2017) }\end{array}$ & $\begin{array}{l}\text { (Ahluwalia, Papadias, } \\
\text { and Wang 2020) }\end{array}$ \\
\hline Maritime & Ammonia & 0.82 & 1 & $\begin{array}{l}\text { (Hydrogen Council } \\
\text { 2021; Concawe } \\
\text { 2017)13 }\end{array}$ & Drop-in fuel \\
\hline Maritime & Methanol & 0.18 & 1 & $\begin{array}{l}\text { (Hydrogen Council } \\
\text { 2021; Concawe } \\
\text { 2017)14 }\end{array}$ & Drop-in fuel \\
\hline Air & Electric & 0.15 & 1.25 & (Schäfer et al. 2019) & $\begin{array}{l}\text { (Schäfer et al. } \\
\text { 2019)15 }\end{array}$ \\
\hline Air & Hydrogen & 0.25 & 1 & $\begin{array}{l}\text { (Hydrogen Council } \\
\text { 2021) }\end{array}$ & $\begin{array}{l}\text { Assume hydrogen } \\
\text { turbines used }\end{array}$ \\
\hline Air & Synfuels & 0.6 & 1 & $\begin{array}{l}\text { (Hydrogen Council } \\
\text { 2021) }\end{array}$ & Drop-in fuel \\
\hline Lubricants & Synfuels & 1 & 1 & Assumption & Drop-in fuel \\
\hline Military & Biofuels & 0.5 & 1 & Assumption & Drop-in fuel \\
\hline Military & Synfuels & 0.5 & 1 & Assumption & Drop-in fuel \\
\hline
\end{tabular}

${ }^{13}$ Ammonia share estimated based on ships with long routes, less frequent stops, no passengers, and lower potential total cost of ownership.

${ }^{14}$ Methanol share estimated based on ships with shorter routes, more frequent stops, potential for passengers, and lower potential total cost of ownership.

${ }^{15}$ Electric aircraft currently have $\sim 2$ times higher propulsion efficiency but are 1.5-2 times heavier due to battery weight. We assume a 1.25 fuel economy ratio, representing the middle of this range. 
Based on the energy efficiency, market share, and fuel efficiency assumptions, the final 2050 deep decarbonization energy usage in the transportation sector is summarized in Table 6 .

Table 6. Approximated Transportation Sector Deep Decarbonization Energy Consumption

\begin{tabular}{|l|c|c|c|c|c|c|}
\cline { 2 - 7 } \multicolumn{1}{c|}{} & \multicolumn{6}{c|}{ Final Demand by Fuel Type (Quads) } \\
\hline AEO Subsector & Electric & Hydrogen & Biofuels & Synfuels & Ammonia & Methanol \\
\hline Motorcycles & 0.01 & 0.00 & 0.00 & 0.00 & 0.00 & 0.00 \\
\hline Light-Duty Vehicles & 1.13 & 0.00 & 0.00 & 0.00 & 0.00 & 0.00 \\
\hline Medium-Duty Trucks & 0.11 & 0.17 & 0.00 & 0.00 & 0.00 & 0.00 \\
\hline Heavy-Duty Trucks & 0.21 & 0.66 & 0.46 & 0.00 & 0.00 & 0.00 \\
\hline Bus & 0.01 & 0.04 & 0.04 & 0.00 & 0.00 & 0.00 \\
\hline Domestic Shipping & 0.00 & 0.00 & 0.00 & 0.00 & 0.02 & 0.01 \\
\hline International Shipping & 0.00 & 0.00 & 0.00 & 0.00 & 0.52 & 0.11 \\
\hline Recreational Boats & 0.00 & 0.00 & 0.00 & 0.00 & 0.25 & 0.05 \\
\hline Freight Rail & 0.00 & 0.09 & 0.20 & 0.20 & 0.00 & 0.00 \\
\hline Passenger Rail & 0.00 & 0.01 & 0.01 & 0.01 & 0.00 & 0.00 \\
\hline Air & 0.20 & 0.41 & 0.49 & 0.49 & 0.00 & 0.00 \\
\hline Lubricants & 0.00 & 0.00 & 0.00 & 0.13 & 0.00 & 0.00 \\
\hline Military & 0.00 & 0.00 & 0.41 & 0.41 & 0.00 & 0.00 \\
\hline
\end{tabular}

